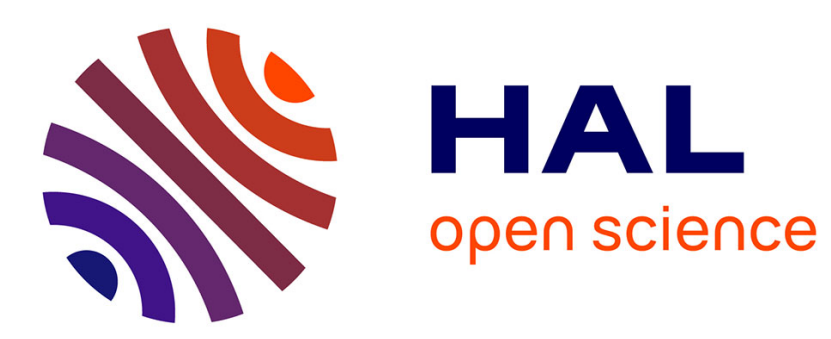

\title{
Apocalypse XXI-XXII et l'iconographie du portail central de la nef de Vézelay
}

Marcello Angheben

\section{To cite this version:}

Marcello Angheben. Apocalypse XXI-XXII et l'iconographie du portail central de la nef de Vézelay. Cahiers de Civilisation Médiévale, 1998, 41 (163), pp.209-240. 10.3406/ccmed.1998.2723 . halshs01195661

\section{HAL Id: halshs-01195661 https://shs.hal.science/halshs-01195661}

Submitted on 8 Sep 2015

HAL is a multi-disciplinary open access archive for the deposit and dissemination of scientific research documents, whether they are published or not. The documents may come from teaching and research institutions in France or abroad, or from public or private research centers.
L'archive ouverte pluridisciplinaire HAL, est destinée au dépôt et à la diffusion de documents scientifiques de niveau recherche, publiés ou non, émanant des établissements d'enseignement et de recherche français ou étrangers, des laboratoires publics ou privés. 


\section{Apocalypse XXI-XXII et l'iconographie du portail central de la nef de Vézelay}

In: Cahiers de civilisation médiévale. 41e année (n¹63), Juillet-septembre 1998. pp. 209-240.

Citer ce document / Cite this document :

Angheben Marcel. Apocalypse XXI-XXII et l'iconographie du portail central de la nef de Vézelay. In: Cahiers de civilisation médiévale. 41e année ( $\left.n^{\circ} 163\right)$, Juillet-septembre 1998. pp. 209-240.

doi : $10.3406 /$ ccmed.1998.2723

http://www.persee.fr/web/revues/home/prescript/article/ccmed_0007-9731_1998_num_41_163_2723 


\begin{abstract}
It is now generally accepted that Pentecost is in fact the theme of the tympanum of the central portal of the nave of the church at Vézelay - Pentecost, an event which was then regarded, as it still is, as the founding act of the Church. Representations of Apostles are seen at various points on the portal, indicating that the Church is already at work, teaching and preaching. In order to evoke the nature of the Church, the creator of the concept for the portal appears to have drawn on the two final chapters of the Apocalypse (21 and 22) and the relevant exegesis. For a characteristic feature of these texts is that pratically ail the component elements of the portal are therein alluded to, either directly or more or less implicitly. And it is from this source that certain of those elements derive their meaning, namely the waters at the feet of Christ ; the throne on which he sits ; the figures carved on the embrasure and the representation of John the Baptist ; and especially the zodiac with its four insets as well as the two capitals on the right-hand side. It is perfectly possible therefore that the conception of the iconographie message of the portai should have taken shape with those chapters of the Apocalypse in mind.

\section{Résumé}

Il paraît désormais établi que le tympan du portail central de la nef de Vézelay est effectivement consacré au thème de la Pentecôte, un événement qui, au moyen âge, était déjà conçu, notamment, comme l'acte fondateur de l'Église. En plusieurs endroits du portail, des figures d'apôtres indiquent que l'Église œuvre déjà par la prédication et l'enseignement. Pour évoquer cette institution, le concepteur semble avoir utilisé les deux derniers chapitres de l'Apocalypse (XXI et XXII), ainsi que l'exégèse qui s'y rapporte. Ces textes présentent en effet la particularité de mentionner, de manière plus ou moins explicite, la quasi totalité des composantes du portail. Ils donnent ainsi un sens à la présence de certaines d'entre elles : les ondulations situées aux pieds du Christ, le trône sur lequel ce dernier est assis, les figures des ébrasements et celle de Jean-Baptiste, et surtout le zodiaque, les quatre médaillons qui l'interrompent et les deux chapiteaux de droite. Ces textes ont donc parfaitement pu servir de fil conducteur dans la conception du programme iconographique du portail.
\end{abstract}




\title{
Marcel ANGHEBEN
}

\section{Apocalypse XXI-XXII \\ et l'iconographie du portail central de la nef de Vézelay*}

\begin{abstract}
RÉSUMÉ
Il paraît désormais établi que le tympan du portail central de la nef de Vézelay est effectivement consacré au thème de la Pentecôte. un événement qui. au moyen âge. était déjà conçu. notamment. comme lacte fondateur de l'Église. En plusicurs endroits du portail, des figures d'apôtres indiquent que l'Église ceuvre déjà par la prédication et l'enseignement. Pour évoquer cette institution. le concepteur semble avoir utilisé les deux derniers chapitres de l'Apocalypse (XXI et XXII), ainsi que l'exégèse qui s’y rapporte. (es textes présentent en effet la particularité de mentionner, de manière plus ou moins explicite, la quasi totalité des composantes du portail. Ils donnent ainsi un sens à la présence de certaines d'entre elles : les ondulations situées aux pieds du Christ, le trône sur lequel ce dernier est assis, les figures des ébrasements et celle de Jean-Baptiste, et surtout le zodiaque, les quatre médaillons qui l'interrompent et les deux chapiteaux de droite. Ces textes ont donc parfaitement pu servir de fil conducteur dans la conception du programme iconographique du portail.
\end{abstract}

\section{ABSTRACT}

It is now generally accepted that Pentecost is in fact the theme of the tympanum of the central portal of the nave of the church at Vézelay - Pentecost. an event which was then regarded. as it still is. as the founding act of the Church. Representations of Apostles are seen at various points on the portal. indicating that the Church is already at work. teaching and preaching. In order to evoke the nature of the Church, the creator of the concept for the portal appears to have drawn on the two final chapters of the Apocalypse (21 and 22) and the relevant exegesis. For a characteristic feature of these texts is that pratically all the component elements of the portal are therein alluded to, either directly or more or less implicitly. And it is from this source that certain of those elements derive their meaning, namely the waters at the feet of Christ: the throne on which he sits; the figures carved on the embrasure and the representation of John the Baptist: and especially the zodiac with its four insets as well as the two capitals on the right-hand side. It is perfectly possible therefore that the conception of the iconographic message of the portal should have taken shape with those chapters of the Apocalypse in mind.

Dans les nombreuses études qui ont été consacrées à l'iconographie du portail central de la nef de Vézelay. on a longtemps cherché à déterminer le sujet du tympan ou à expliciter le sens d'une ou plusieurs composantes de l'ensemble. Des travaux plus récents ont orienté la recherche vers des hypothèses qui tendaient plutôt à montrer les relations existant entre la création de cette

Cette étude sinscrit dans le cadre d'une thèse préparée à luniversité de Paris X-Nanterre sous la direction de Jean-Pierre (aillet. Je tiens à remercier Alain Dierkens et Dominique Iogna-Prat pour la relecture de cet article et les nombreux conseils qu'ils mont prodigdés. Je veux également exprimer ma gratitude à Kristin Sazama pour l’aide quelle ma apportée. ainsi quà Pedro de Sousa Pernes pour la traduction anglaise du résumé. 
(xuvre et l'histoire ou l'idéologie contemporaines '. Mais aucun ne semble être parvenu à expliquer la totalité des éléments constitutifs du portail en partant d'un fil conducteur qui conférerait à l'ensemble une cohérence et un sens global. Or, si l'on admet que le programme iconographique a fait l'objet d'une élaboration savante. chargée d'une ou plusieurs intentions précises, comme beaucoup d'auteurs l'ont soutenu, il paraît logique de penser que ce programme s'étend à toutes les parties du portail, y compris les chapiteaux.

Je soutiendrai ici que c'est la description de la Jérusalem céleste dans l'Apocalypse et ses commentaires qui ont dû jouer ce rôle de fil conducteur. Pour le montrer, il sera nécessaire de revenir brièvement sur la problématique relative au sujet du tympan, avant d'examiner point par point toutes les parties du portail en les confrontant à la dernière vision de l'Apocalypse.

\section{Pentecôte ou Mission des apôtres.}

Le grand portail de la nef de Vézelay [fig. 1] présente un programme d'une richesse iconographique exceptionnelle : au tympan, le Christ trônant. inscrit dans une mandorle, étend ses mains d'où partent des rayons en direction des douze apôtres. De part et d'autre de la figure centrale et sous les pieds des apôtres se trouvent des ondulations aux formes diverses. Autour de ce premier ensemble, huit compartiments disposés en éventail abritent de nombreux personnages dont certains sont d'aspect monstrueux tandis que d'autres paraissent infirmes. Sur le premier rouleau de la voussure est sculpté un zodiaque accompagné des travaux des mois. Sur le linteau, deux processions convergent vers deux grandes figures : saint Pierre et peut-être saint Paul. Jean-Baptiste apparaît debout au pilier central: il tient un médaillon où figurait l'Agneau aujourd'hui disparu, tandis que des apôtres occupent les faces internes de ce même pilier ainsi que les ébrasements dont les colonnettes sont couronnées par quatre chapiteaux historiés.

On a longtemps discuté à propos du thème central, hésitant entre la Pentecôte et la Mission des apôtres, cherchant quelquefois à concilier les deux interprétations ${ }^{2}$. C"est cette dernière hypothèse que je retiendrai : la scène du tympan représenterait la Pentecôte. suivie aussitôt par le début de l'ouvre missionnaire des apôtres. Ce qui a le plus embarrassé dans la lecture de cette image, c'est la présence du Christ au milieu des apôtres : c'est pourquoi certains ont pensé à l'apparition qu'il fit au cénacle avant l'Ascension ${ }^{3}$.

Une certaine confusion règne en effet dans les Écritures au sujet de l'ordre des événements : pour Matthicu, Marc et Jean. le Christ envoya ses disciples en mission avant de monter au ciel (Mat. 28, 16-20: Mc 16, 12-18; Jn 20, 21), alors que dans l'Évangile de Luc et dans les Actes qu'au moyen âge on attribuait déjà au même évangéliste. il leur demande d'attendre la venue du Paraclet (Lc 24, 49; Actes 1, 4-5). Dans les Actes, c'est bien après le discours de saint Pierre que les apôtres ont commencé leur œuvre. L’Évangile de Jean enfin (20, 22) introduit une confusion supplémentaire dans la mesure où il suggère une première descente du Saint-Esprit. directement après l’annonce de la Mission. Contrairement à Matthieu et à Marc. Jean évoque à

1. M. D. Taylok. "The Pentecost at Vézelay», Gesta. XIX/1, 1980, p. 9-15: - M.-L. Thŕki:.. "À lorigine du décor du portail occidental de Notre-Dame de Senlis : le triomphe de la Vierge-Église. Soures historiques. littéraires et iconographiques". Paris. 1984. p. 280-285: - P. Diems:. "Das Pfingstportal von Vézelay - Wege. Umwege und Abwege ciner Diskussion". Jahrhuch des Zentralinstituts fiir Kunstgeschichte. I. 1985. p. 77-114: - J. S. FEL.DMAx, "The Narthex Portal at Véyelay : Art and Monastic Self-Image" [thèse dactyl.]. Austin. Univers. of Texas, 1986; - K. SAZAma. The Assertion of Monastic Spiritual and Temporal Authority in the Romanesque Sculpture of Sainte-Madeleine at Vezclay lthese dactyl.). Evanston, North-West Linivers.. 1995.

2. Dis.mik. "Das Pfingstportal...". (voir n. 1). p. 82-89. a fait un résumé trés complet de la longue polémique qua suscitée ce probleme.

3. Coositu:r. "Iconographie de l'église de Vézelay". Congrès archéologique de France, 14. Paris. 1847, p. 219-230. "u en particulier. p. 266: - et surtout A. Fabri:. "L Liconographie de la Pentecôte. Le portail de Vézelay. les fresques de Saint-Gilles de Montoire et la miniature du 'lectionnaire de Cluny" ". (jasette de's Beatu-Arts. 65. 1923. p. 33-42. qui est

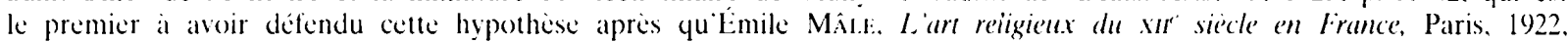
p. 236 et ss, eut défendu la thèse de la Pentecôte. avec des arguments renforcés par rapport a la première édition. Il a été suivi par plusicurs auteurs : voir la discussion che\%. P. Drr.sir. "Das Pfingstportal..." (voir n. 1). p. 82 et ss. 


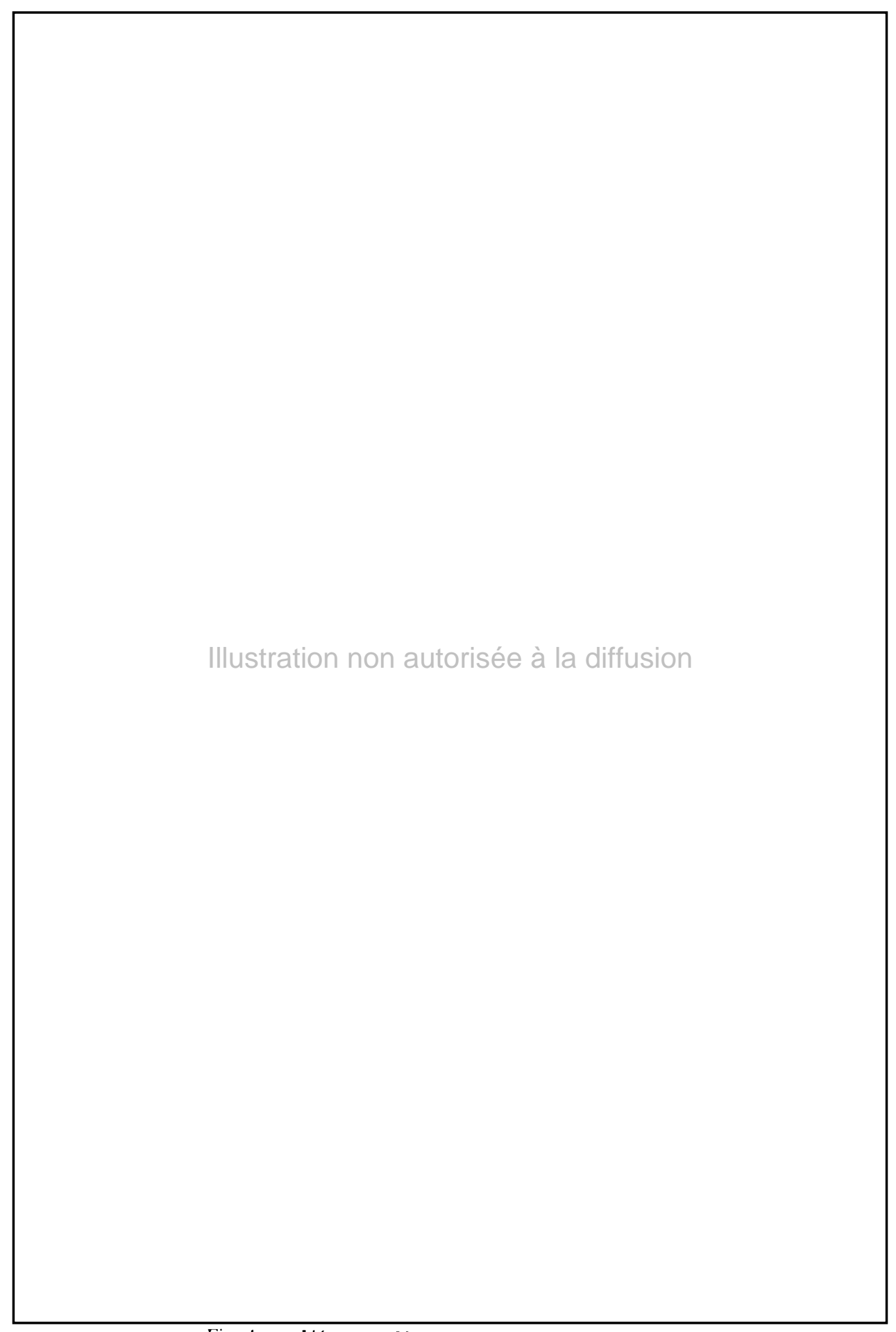

Fig. 1. - Vézelay (Yonne). La Madelcine. Narthex. Portail central de la nef. Vue densemble.

(Cliche Paris, Caisse Vat. Momum. Histor., nég. 52 P 247.) 
plusieurs reprises lannonce de la venue du Paraclet. C'est done en toute logique qu'il décrit. à la fin de son Évangile, le Christ donnant le Saint-Esprit à ses apôtres, mais ici l'événement précède l’Ascension. La sculpture du tympan pourrait donc découler du récit de saint Jean et représenter la Mission suivie directement de l'envoi du Paraclet. Les trois portails devraient dès lors être lus de droite à gauche : l'Ascension évoquée sur le portail nord succéderait ainsi à la Nativité du portail sud et à la Mission, doublée de l'envoi du Paraclet, du portail central. Céla amène presque obligatoirement à écarter l'Évangile de Luc et les Actes, à moins de supposer qu'un deuxième envoi de l'Esprit-Saint suivra l'Ascension. Abel Fabre, qui a soutenu l'hypothèse de la Mission, n'a pourtant retenu que les Évangiles de Matthicu et de Marc comme sources scripturaires, ce qui suppose un seul envoi, celui qui précède l'Ascension ${ }^{4}$.

Accepter cette interprétation implique en outre que l'on ignore plusicurs autres sources. et surtout les pratiques liturgiques. Or, l'incidence de la liturgie sur la perception quavaient les cleres d'un épisode de la vie du Christ aussi important que la Pentecôte. devait être capitale. Il convient dès lors de résumer brièvement les arguments favorables à la première hypothèse, et de les compléter par de nouveaux.

Pour commencer, il y a les représentations contemporaines de la Pentecôte, et en particulier celles du lectionnaire de Cluny et du sacramentaire de Saint-Étienne de Limoges, rattaché lui aussi au milieu clunisien ${ }^{5}$. Elles montrent que le Christ peut parfaitement se trouver au centre de la composition en tant que source des langues de feu.

Ensuite, il y a les textes : là aussi. le Christ peut être lacteur principal de la Pentecôte ${ }^{6}$. Dans les Actes, saint Pierre précise que c'est le Christ qui a envoyé l'Esprit-Saint $(2,32)$. Les Évangiles de Luc et de Jean avaient déjà annoncé que c’était Jésus lui-même qui devait envoyer le Paraclet à ses apôtres (Lc 24, 49; Jn 14, 16 et 26;15, 26;16,7-15). L'idée sera régulièrement développée dans les commentaires et les sermons. Dans son homélie pour le dimanche qui précède la Pentecôte, Héric d'Auxerre, rappelant que la volonté du Père n'est pas séparable de celle du Fils, affirme même que ce sont les deux premières personnes de la Trinité qui ont envoyé le Saint-Esprit ${ }^{7}$.

La liturgie, pour sa part, a dû jouer un rôle très important dans la diffusion de cette idée. Le coutumier de l'abbé Odilon, intitulé Liber tramitis, mentionne qu’à Cluny, le samedi qui suit la Pentecôte, on lisait ceci : ...spiritus sanctus... quem dominus noster iesus christus misit in terram ${ }^{8}$.

4. Fabre. "L Liconographie de la Pentecôte..." (voir n. 3). p. 40 et ss.

5. De nombreux exemples dont le lectionnaire de Cluny sont fournis par S. SFft.ligi:R. "Das Pfingstbild mit Christus im 6-1.3 Jahrhundert ". Das Mïnster. 5/6. 1956. p. 146-152. Voir également G. Schituler. Ikomographie der christlichen Kunst, IV. 1. Gütersloh, 1976. p. 27 el ss: - et Feldoman, "The Narthex Portal..." (voir n. 1), p. 78. Pour le sacramentaire de Saint-Étienne de Limoges. J. Porcher. Le sacramentaire de Saint-Étienne de Limoges, Paris. 1953: - et D. Gaborit-C 'uopix. La decoration des manuscrits a Saint-Martial de Limoges et en Limousin du xr' au xur' s., Paris/ Genève. 1969. p. 125 et ss. L'exemple de Sant Joan de Bellcaire. en Catalogne. est particulièrement intéressant : sur la peinture murale. déposée au musée épiscopal de Gérone. Dieu le Père et le Christ trônants se trouvent au-dessus des apotres et ils envoient. mains tendues vers le bas. IEsprit-Saint qui se manifeste sous la forme dune colombe et de langues de feu: ef. J. Si:REDA. "La pintura romanica en Cataluña». Madrid. 1989. p. 295. On remarquera les ondulations entre la Trinité et les apôtres. comparables a celles de Vézelay. De plus. la présence du Père et du Fils est peut-être une allusion au filioque'.

6. TAYior. "The Pentecost at Vézelay" (voir n. 1). p. 13. cite l'Occupatio dodon de cluny.

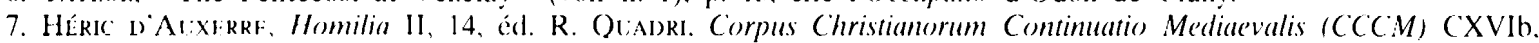
p. 118. La bibliothèque de ("luny possédait le volumineux homéliaire d'Heric ( $\mathrm{n}^{\prime \prime} 425$ du catalogue). cf. L. Dit.IsI.\&. Le

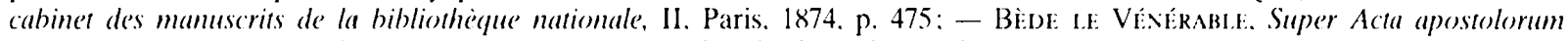
expositio II. PI. 92. 946 (-D. reprenant le commentaire de Grégoire le Grand. explique que c'est le (hrist qui apparut sous la forme des langues de feu. Les exégetes profitent parfois de cette occasion pour rappeler le dogme trinitaire dans lequel le Saint-Esprit procède à la fois du Père et du Fils. contrairement à ce que pensent les "Grecs". cf. Reptrkr. Commentaria in erangelium sancti lohamnis (in loh.) XII. 15. 26-27. éd. R. HAACKE. CCCM IX. p. 668-672: - TAYioR. "The Pentecost at Vézelay" (cf. n. 1). p. 11. pense pour cette raison que le portail fait référence au concile de Bari (1098) ou le filioque fut réalfirmé contre lopinion de l'F́glise d'Orient.

8. Liber Tramitis (L.T), 76.4. éd. P. DINIE. Corpus consuetudinum monasticartum (CC.M). X. Siegburg. 1980), p. 118: cf. "Sacramentaire grégorien". éd. Deshusses. Le sacramentaire grégorien. Ses principales formes, daprès les plus ancienss manuscrits. I : Le sacramentaire, le supplement d'Aniane. Fribourg. 1971 (Spicilegium Friburgense. 16). n. 546. 
Tout cela montre suffisamment que, dans le contexte clunisien, et sans doute par extension à Vézclay, on a conçu l'événement et sa représentation comme dans le lectionnaire et sur le tympan.

Quant à l'envoi du Saint-Esprit en deux temps, certains exégètes sont conscients de la contradiction que cela implique, mais ils ne parviennent pas toujours à en fournir une explication satisfaisante".

Dans la liturgie en revanche. on semble avoir trouvé la solution en rapprochant les deux récits lors de la même solennité. En effet. toujours à Cluny. on lisait, pour les vigiles du dimanche de la Pentecôte, une homélie de saint Augustin tirée de son commentaire sur l'Évangile de saint Jean ${ }^{10}$. Or, le passage commenté est précisément celui qui relate la première émission du Saint-Esprit. C'est du reste ce sermon qu'illustre la miniature du lectionnaire de Cluny. On a donc choisi l'ordre des événements tel qu'il a été établi dans l'Évangile de Luc et dans les Actes, et on y a associé le texte de Jean, faisant ainsi disparaître les incohérences signalées dans les Écritures.

Il faut ajouter que si la scène de Vézelay représentait l'apparition que fit le Christ au cénacle décrite par saint Jean, on voit mal pourquoi l'on aurait placé ce dernier dans une mandorle, l'épisode se déroulant sur terre.

La distinction entre Pentecôte et Mission des apôtres devait d'ailleurs être moins importante qu'on a pu le penser ${ }^{11}$. On verra plus loin comment le second thème a pu se mêler au premier.

\section{la Pentecôte comme fondation de l'Église et de la Jérusalem céleste.}

Il est bien connu que, pour de nombreux auteurs du moyen âge, l'Église a été fondée le jour de la Pentecôte et que, dès l'origine, elle a été appelée à se répandre sur la terre entière ${ }^{12}$. Mais la Pentecôte est aussi la victoire de la Jérusalem céleste sur Babylone ${ }^{13}$. Les commentaires de l'Apocalypse soulignent en permanence cette équivalence entre l'Église et la Jérusalem céleste ${ }^{14}$. Saint Augustin, dans la Cité de Dieu, situe même la fondation de la Cité sainte le jour où les eaux salutaires de la grâce sont venues du ciel avec le Saint-Esprit ${ }^{15}$. Autrement dit, depuis le jour de la Pentecôte, la Jérusalem céleste est présente sur terre. même si sa victoire définitive sur Babylone n'aura lieu qu’à la fin des temps.

9. SAINT Augusin, Tractatus in lohannis evangelium (in Ioh.), 74, 2. éd. Bibliothèque augustinienne (BA). 74 A. p. 32()-322. Inventaire de la bibliothèque de (luny. n. 128. cf. Destisi.f. Le cabinet des mamuscrits... (cf. n. 7). p. 46.3. Pour RuPE:RT, in loh. XIV, 20, 22-23. CCCM IX. p. 773, la première fois. le Saint-Esprit procède du Fils pour la rémission des péchés. la deuxième. il est donné par le Père pour les honneurs des différentes grâces. Et de rappeler que les "Grecs" ne croient pas que le Saint-Esprit procède du Pere et du Fils.

10. Salvi Auglstin. in loh. 74. BA. 74 A. p. 314-329. cf. LT 75. CCM X. p. 114: cet argument a été avancé. contre

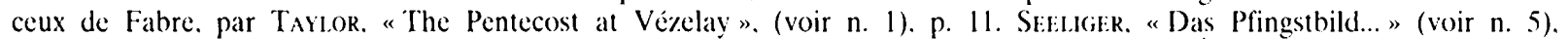
p. 148. rappelle pour sa part que. pour la fête de la Pentecôte. on lisait deux passages de l'Évangile de saint Jean où le Christ promet le Paraclet (14, 16 et 26).

11. DiEmE. "Das Pfingstportal..." (voir n. 1). p. 88.

12. R. Cabié. La Pentecôte. L’évolution de la cinquantaine pascale au cours des cinq premiers siècles. Tournai. 1965. p. 87. et larticle "Pentecôte". dans Dictionnaire de spiritualité ascétique et mystique, doctrine et histoire (DS). fasc. 78-79. Paris. 1984. col. 1035. On a également conçu que l'Église était sortie du côté ouvert du (hrist. au moment de la Crucifixion. Pour saint Augustin. son établissement se fit progressivement entre l'Incarnation et la Pentecote. cf. E. Lamiraxide, L'Eglise céleste selon saint Augustin. Paris, 1963, p. 126.

13. (Abif́. La Pentecôte... (voir n. 12). p. 230-231 : lauteur y cite les sermons 268 el 271 de saint Augustin.

14. (3. Lobkichon. L'Apocalypse des theologiens du xir siecle [thèse dactyl.]. Paris. EHFSS. 1979. p. 140.

15. De Civitate Dei XX. 17. BA 37. 1960. p. 268-269. Pour les rapports entre Cité de Dieu et Église. voir Y.-J.-M. CoNgink. "Civitas Dei et Ecclesia chez saint Augustin". Revue des études augustimiennes. II. 1, 1957. p. 1-14: et L'ecclésiologie du haut moyen âge. De saim Cirégoire le Grand à la désunion éntre Byzance é Rome. Paris. 1968. p. 121 et ss. 
On retrouve cette association Apocalypse-Pentecôte dans le Tractatus de dedicatione ecclesiae, une ceuvre antérieure au milieu du $\mathrm{IX}^{\mathfrak{e}} \mathrm{s}$., autrefois attribuée à Rémi d'Auxerre ${ }^{16}$. Ce texte est d'autant plus important qu'il évoque la fondation des églises, et que ces dernières sont l'expression matérielle de l'Église. L'autcur, recopiant un passage de saint Augustin. rappelle qu'en effet le même mot est utilisé pour désigner le contenant et le "contenu» ${ }^{17}$. On ne s'étonnera donc pas de ce qu'au début de son traité. lorsqu'il explique la signification des douze chandelles qu'on allume avant que l'évêque n'entre dans l'église, l'auteur fasse allusion à la Pentecôte. Pour commencer, il compare la dédicace de l'église à celle du temple de Salomon. son modèle, au cours de laquelle les douze chefs des tribus d'Israël sont venus apporter leurs offrandes. Ces chefs sont comme les douze apôtres qui. après avoir reçu l'Esprit-Saint, ont évangélisé les nations et ainsi œuvré à l'édification de l'Église. Ensuite, reprenant deux images de l'Apocalypse fondues en une, l'auteur explique que les chandelles sont "irriguées» par la source du Saint-Esprit, dont les fruits sont consacrés à la consommation et les feuilles destinées à gućrir les nations, apportant chaque mois leurs prémices ${ }^{18}$. On aura reconnu la source d'eau vive el l'arbre de vie d'Apocalypse 22, 1-2. Il apparaît par ailleurs assez clairement que les douze chandelles sont une image des douze apôtres recevant l'Esprit-Saint le jour de la Pentecôte. Cet événement est donc commémoré symboliquement, dans la cérémonie de la dédicace, pour montrer que la fondation d'une église est comparable à celle de l'Église. Et si l'on fait référence à l'Apocalypse, c'est parce que le bâtiment, comme la communauté des croyants, est un équivalent de la Jérusalem céleste, ce qu'atteste la liturgie en usage à Cluny. Dans les coutumes de Bernard. contemporaines de l'abbé Hugues, on lisait pour la fête de la dédicace de l'église la dernière section récapitulative de l'Apocalypse où est décrite la Cité sainte : Vidi civitatem... $(21,2)^{19}$. Cela montre suffisamment l'évidence que devait présenter cette équivalence aux yeux des moines qui lisaient ee traité sur la dédicace de l'église.

L'association Apocalypse-Pentecôte se retrouve enfin dans la liturgie clunisienne. À la messe de l'octave de la Pentecôte. on lisait Apocalypse IV, à savoir la deuxième vision qui met en présence l'Être sur le trône, les vingt-quatre Vieillards, les quatre Vivants. les sept lampes, etc. Il s'agit d'une des rares lectures - neuf au total - de l'Apocalypse prescrites par le Liber tramitis. Or, pour cette célébration. il est demandé de placer sept candélabres devant l'autel et trois derrière ${ }^{20}$. Le chour de Cluny II devait alors ressembler de très près à la vision apocalyptique avec le cul-de-four où, comme à Cluny III, trônait peut-être un Christ en gloire entouré par les quatre Vivants ${ }^{21}$, et surtout avec les sept lampes allumées devant l'autel.

16. Au IX $X^{\circ}$ s., il n'existe que deux commentaires sur le rite de la dédicace. le second est celui d'Almanne d'Hautvillers. cf. J.-P. Bounor, "Les sources de l'Expositio missae de Rémi D’Auxerre", Revue des études augustiniennes, XXVI. 1-2. 1980. p. 118-169.

17. PL 131. 847 B. La citation de saint Augustin est celle de la lettre CXC. 5. 19. éd. A. Golbacher. Corpus scriptorum ecclesiasticorum !atinorum (CSEL) 57. p. 154.

18. PL 131. 845-846 A. La cérémonic de la dédicace est décrite dans l’ordo XI.I. cf. M. AxprIf:i, Les "ordines romani " du haut moyen age. IV. Paris. 1956. p. 315-349.

19. Ordo cluniacensis, éd. M. Hercort, dans Vetus disciplina monastica. Paris. 1726. p. 134-364. el en particulier p. 298 pour la dédicace de l'église. Pour les coutumes de Bernard et d'Llrich, voir J. Wollasch, "Zur Verschriftlichung der klösterlichen Lebensgewohnheiten unter Abt Hugo von Cluny ». Frïhmittelalterliche Studien, 27, 1993. p. 317-349: - et D. IogNa-Prat, "État des travaux sur les textes narratifs et réglementaires ( $\mathrm{X}^{*}$-XII" $\mathrm{s}$.) ", dans les études clumisiennes dans tous leurs états. Rencontre de Cluny, 21-22 septembre 1993. Notes critiques, Revue Mabillon, nouvelle séric. t. 5.1994. p. 233-265. p. 244. Cette lecture était déjà prescrite à l’époque d’Odilon. cf. $L T$ 136. CCCM X. p. 196-197. Pour les rapports entre l'Apocalypse et la liturgie, voir C. CiffFord Flasigan, "The Apocalypse and the Medieval Liturgy", dans R. K. Emmerson et B. Mc Giss, ed. The Apocalypse in the Middle Ages, Ithaca/Londres, 1992, p. 333-351.

20. $L T$ 76. 5: CCCM X. p. 120 .

21. K. J. Conant. Cluny. les églises et la maison du chef d'ordre. Mâcon. 1968. fig. 32 et 83: - H. Parkiar. Peintures mruales du moven age et de la Renaissance en Bourgogne du sud. Ëude technique et iconographique. Montceau-les-Mines. 1974. p. 5-6: - et J. Kagin. "Sussev-le-Maupas". dans D'ocre el d'azur. Pcintures murales en Bourgognce (catal. exposition itinérante, 1992]. Paris. 1992, p. 159. Pour une mise au point du débat concernant Cluny II, voir C. SAPIN. "Labbatiale de Cluny II sous saint Hugues". dans Le gouvernement d'Hugues de Semur à CLuny (Actes du colloque scientifique international. (luny. 1988). 1990, p. 435-460. 
Or, si l'on interroge l'exégèse de l'Apocalypse, on apprend que ces lampes peuvent évoquer le Saint-Esprit, la Pentecôte et le baptême ${ }^{22}$. Donc même si ce n'est pas directement la Jérusalem céleste qui est concernée dans cette lecture, il reste que, dans la pratique liturgique. les clunisiens ont associé la Pentecôte et une vision de l'Apocalypse ${ }^{23}$ :

Cette association m'amène donc à formuler l'hypothèse suivante : le concepteur ${ }^{2+}$ du programme. cherchant à montrer à la fois l'Église et l'acte de fondation qui l'a vu naître. a choisi comme fil conducteur la description de la Cité sainte dans la dernière section récapitulative de l'Apocalypse. Yves Christe a justement rappelé qu'il ne fallait pas tenir compte de la subdivision actuclle en chapitres. et qu'il ne fallait pas non plus rattacher cette dernière vision uniquement à la fin des temps. En effet dans les commentaires, la Jérusalem céleste peut présenter trois aspects différents : clle est la Cité céleste idéale déjà présente, le modèle de l'Ecclesia terrena luttant pour son accomplissement définitif, ou encore la Cité à venir, réunion de l'Ecclesia superna et de l'Église terrestre arrivée au terme de sa pérégrination ${ }^{25}$.

Si l'objectif du concepteur fut réellement d'évoquer ces différents aspects. cela confirmerait que lïiconographie du portail ne se ramène pas exclusivement à l'épisode des Actes. mais se rapporte également au moment ou l'œuvre fut sculptée.

L'analyse qui va suivre s'appuie sur plusieurs commentaires de l'Apocalypse et des Écritures en général. Il y sera fait une place toute particulière aux auteurs carolingiens et en particulier à ceux de l'école d'Auxerre dont on connaît l'influence sur la culture clunisienne ${ }^{26}$. En effet, une section entière de la bibliothèque de Cluny était consacrée aux ouvrages de l'école d'Auxerre qui avaient été apportés par l'abbé Odon. Lui-même était un élève de Rémi ${ }^{27}$. L'œuvre de Rupert de Deutz sera également prise en considération, même si elle ne fut écrite que quelques années avant que l'on ne travaille au portail ${ }^{28}$. Le catalogue de la bibliothèque de Cluny mentionne en effet son

22. Primasilis fipiscoptis Hadrumtinus, Commentarius in Apocalypsin (in Apoc.) 1. 4. 5. éd. A. W. Adams. Corpus Christianorum Series Latina (CCSL) X(11. p. 49:- AmbroIse AuTPERT, Ambrosii Autperti opera Expositionis in Apocalypsin libri $X$ (in Apoc.) III, 4, 5b-6a. éc. R. Webir, CCCM XXVII, p. 214. Ouvrage mentionné dans l'inventaire de la bibliothèque de Cluny ( $\mathrm{n}^{\prime \prime}$ 354-355), cf. Delisle, Le cabinet des manuscrits... (voir n. 7). p. 472: - HAYMON 1) AlXERRE,

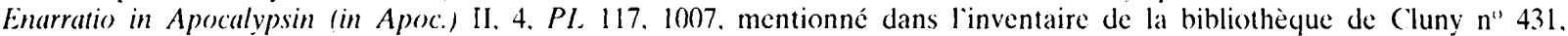
cf. Del.ISL.E. ibid.. p. 475 .

23. Il faut toutefois remarquer que le lien Pentecote-Apocalypse ne se trouve pas dans les textes suivants, liés pourtant à Cluny ou à Vézelay : le sermon pour le jour de la Pentecôte d'Haymox. Homilia "Barré n" H II 16". PL 118. 556-562: - Odilon, Sermo IX in die Pentecostes, PL 142. 1014-1019: - Jut.rex de: Vézellay. Sermo XII, éd. D. Vorkbtx. SC 192. p. $252-263$.

24. Je parlerai régulièrement du coneepteur en sachant quil est impossible de préciser à quelle réalité ce terme se rapporte : il a pu y avoir plusieurs concepteurs, ainsi qu'une collaboration avec les sculpteurs ou leur maître, etc.

25. Y. Curistr. L'Apocalypse de Jean. Traditions exégétiques et iconographiques IIr-xur' siècles. Genève. 1979. p. 129: et "Et super muros eius angelorum custodia». Cahiers de civilisation médiévale. XXIV, 1981. p. 175: et plus récemment. LApocalypse de Jean. Sens et développement de ses visions synthétiques. Paris, 1996. p. 57. Voir aussi (. MAz:dicco, "La Gerusalcmme celeste dell Apocalisse nei Padri". dans M. L. Gatri Perer. éd.. "La dimora di Dio con gli uomini" (Ap). 21. 3). Imagini della Gerusalemme celeste dal III al XIV secolo, Milan. 1983. p. 49-75.

26. V. von Bërex, "Le grand catalogue de la bibliothèque de CLuny". dans le gouvernement d'hugues de Semur... (voir n. 21). p. 245-261: - D. Iogiva-Prat. C. Jeudy et G. Lobrichos. éd.. Lécole carolingienne dAuxerre. de Muretach à Rémi : 830-908 [Entretiens d'Auxerre. 1989]. Paris. 1991.

27. M.-C. GARA.ND. "Une collection personnelle de saint Odilon de Cluny et ses compléments". Scriptorium. XXXIII. 1979. p. 163-180). et en particulier p. 165 et p. 179: - D. IOG.NA-PRAT. Agni immaculati: recherches sur les sources hagiographiques relatives à saim Maieul de Clumy 1954-994). Paris. 1988. p. 131. et pour l'influence d'Héric sur le Sermo de beato Maiolo. p. 55-56. et p. 121 et ss. Lexemplaire clunisien du Commentaire sur l'Apocalypse dllaymon a été conservé (Paris. BNF. nouv. acq. 1453). Ce manuscrit a été daté du dernier quart du $x^{*}$ s.. cf. M.-('. (iakaNi). "('opistes de Cluny au temps de saint Maieul (948-994)». Bibliothèque de l'École des Chartes. (XXXVI. 1978. p. 5-36.

28. Le De Sancta Trinitate et operibus eius a été écrit entre 1112 et 1116 . et le traté In Apocalypsin. entre 1119 et 1121. cf. J. H. VAN Exciex. Rupert of Deutz. Los Angeles/Londres. 1983. p. XIX. et p. 275 et ss. F. Silti. "La Madeleine de Vézelay et ses dates de construction". Bulletin momumental, 95. 1936. p. 5-25. et "Notes sur la façade de la nef". ibid. 99. 1940). p. 223-237. situe la date du portail aux alentours de 1140/50. Pour L. Salinil: et N. Stratfort). La sculpture oubliée de Vézelay. Paris. 1984. p. 76. le portail daterait des années 1120. Certains font remonter la date plus haut, jusquen 1096 : voir la discussion dans Fridmax. The Narthex Portal... (voir n. 1). p. 12 et ss. (C. E. AkmI. Masons and Sculptors in Romanesque Burgundy. The New Aesthetic of Cluny III. Lniversity Park/Londres. 1983. p. 186-187. propose une datation complexe. fondée sur la distinction entre trois campagnes. La première est située entre $1094 / 95$ et 
De Trinitate ${ }^{29}$, mais on ne sait malheureusement pas à quel moment cet ouvrage a été ajouté à la liste rédigée sans doute sous l'abbatiat de saint Hugues. De plus, son commentaire sur l'Apocalypse n'est pas mentionné, mais on peut supposer que le concepteur avait pu prendre connaissance de son contenu dans une autre bibliothèque ou, pourquoi pas, à Vézelay même. En revanche, la plupart des autres ouvrages cités sont répertoriés dans le catalogue clunisien.

\section{Analyse détaillée du portail.}

\section{Le Christ trônant et l'Agneau.}

La partie centrale du tympan est sans doute celle qui dépend le moins de l'Apocalypse. Elle accucille en effet la scène principale de la Pentecôte [fig. 2]. L'Apocalypse permet toutefois d'expliquer la présence du trône dans cette scène et, par extension, la figure de Jean-Baptiste portant l'Agneau.

Après avoir décrit la Jérusalem céleste, l'auteur de la vision évoque le trône de Dieu et de l'Agneau. Dans un premier temps (Ap. 22,1), il est dit qu'un fleuve d'eau vive en jaillit. Pour Haymon d'Auxerre, ce trône doit être compris comme étant celui du Fils de Dieu. Il représente en outre l'Église, de laquelle jaillit la prédication ${ }^{31}$. Plus loin, il est question des trônes de Dieu et de l'Agneau (Ap. 22.3). Cette fois, il y en a deux, parce que l'Église, explique Haymon, est représentée par un trône, à cause de l'unité de la foi, et par deux trônes, à cause de la diversité des nations ${ }^{31}$.

Dicu et l'Agneau, tels qu'ils sont décrits, se trouvent à l'intéricur de la ville dont ils sont le temple (Ap. 21,22), c'est-à-dire l'Église. Cette dernière possède un temple matériel, à savoir un lieu de prière où se réunissent les fidèles pour entendre la parole divine et célébrer les sacrements du Christ. Mais la Cité céleste n’aura pas besoin de temple visible, parce que le Père et l'Agneau seront ce temple ${ }^{32}$.

On peut déduire de ces trois passages et de leurs commentaires que le trône du Christ de Vézelay peut être assimilé à celui de la première description. Là, en effet, il n'y a qu'un seul trône d'où coule le fleuve d'eau vive qui, sur le portail, se répand aux pieds des apôtres.

Le trône du Fils de Dieu est l'Église; or, sur le tympan, il apparaît comme un édifice en réduction : une série d'arcades repose sur des pilastres dont un seul est visible. Si l'on restitue ces formes sur les quatre faces du trône, on obtient un édifice très proche de la civitas quadrata qu'est la Jérusalem céleste ${ }^{33}$. Cette forme de trône n'est évidemment pas exceptionnelle, mais dans la mesure où ici le fleuve d'eau vive y est associé, il est possible que l'un comme l'autre renvoient à l'Apocalypse.

L'Agneau de la vision est également présent au portail : il était sculpté sur le médaillon porté par Jean-Baptiste [fig. 6]. Les inscriptions, lisibles autrefois autour du nimbe de l'Agneau et sur

1104. la deuxième entre 1110 et 1120 , et la troisième après l'achèvement du vaisseau central de la nef, sans que la date de ce dernier ne soit précisée.

29. N" 368. cf. Deliste. Le cabinet des manuscrits... (voir n. 7), p. 473. Voir aussi V. von Büres, "Le catalogue de la bibliothèque de Cluny du $\mathrm{XI}^{\mathrm{L}}$ s. reconstitué ». Scriptorium, 46/2, 1992, p. 256-267 : clle soutient que ce cataloguc a été réalisé sous l'abbatiat de saint Hugues.

30. In Apoc., VII, 22, PL 117, 1211 C.

31. Ibid., 1213 C. Commentaire repris à Ambroise Autpert, in Apoc. X. 22, 3b. CCCM XXVII A. p. 839. On trouve dans ce commentaire une première allusion aux nations représentées sur le portail.

32. In Apoc. VII, 21, PL 117. 1208 D-1209 A.

33. Pour les représentations de la Jérusalem céleste sous une forme architecturale, voir notamment M.-T. GoussEt, "La représentation de la Jérusalem céleste à l'époque carolingienne". Cahiers archéologiques, 23, 1974, p. 47-60); ct "Un aspect du symbolisme des encensoirs romans : la Jérusalem céleste », ihid.. 30. 1982. p. 81-106: - A. C. EsmeiJer. Divina quaternitas. A Preliminary Study in the Method and Application of Visual Exegesis, Assen/Amsterdam, 1978. p. 73 et ss: - et M. Rossi et A. Rovetra, "Indagini sullo spazio ecclesiale. Imagine della Gerusalemme celeste ". dans M. L. GatrI Prerf.r. éd.. "La dimora di Dio... " (voir n. 25). p. 77-115. 


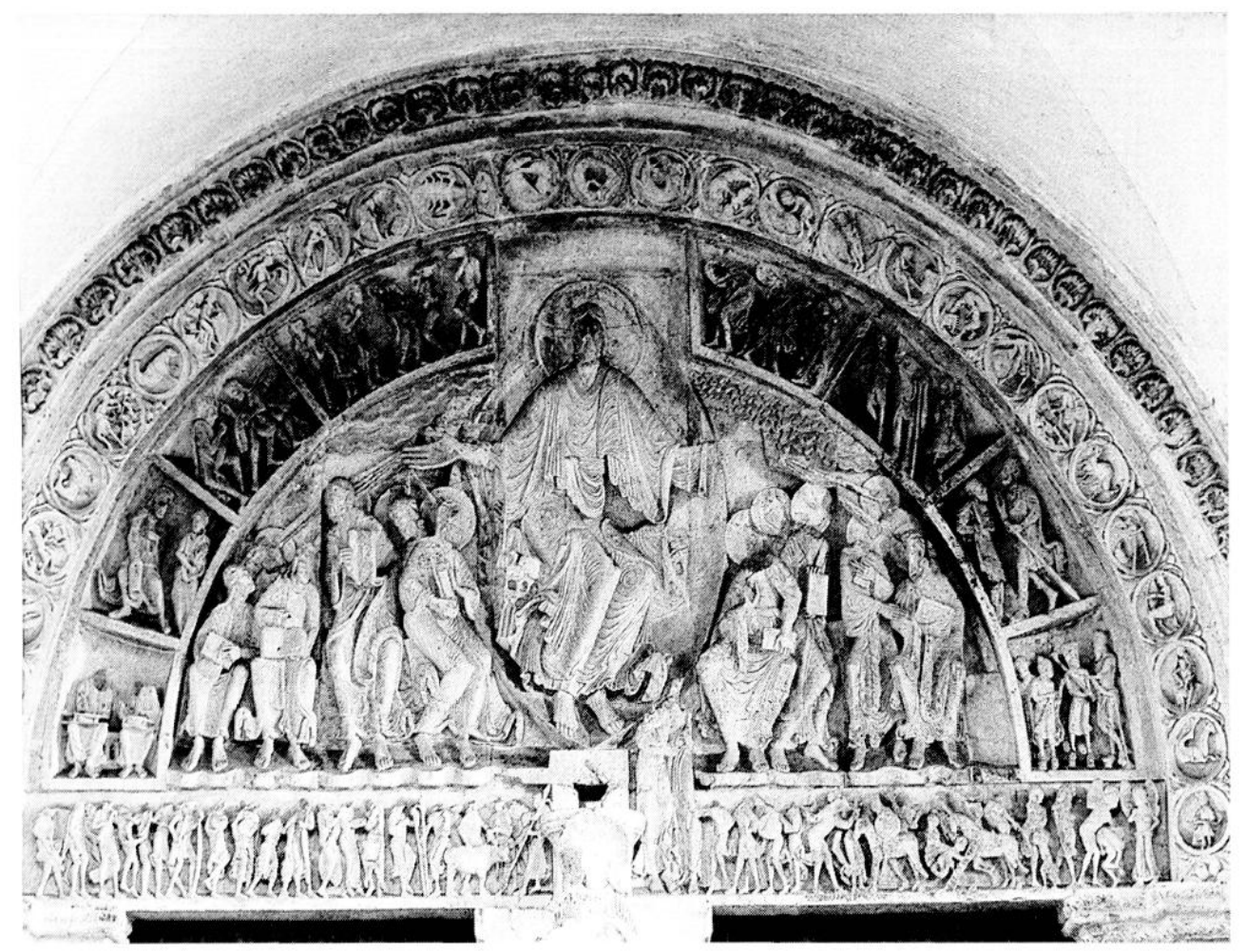

Fig. 2. - Vézt:aY (Yonne). Tympan.

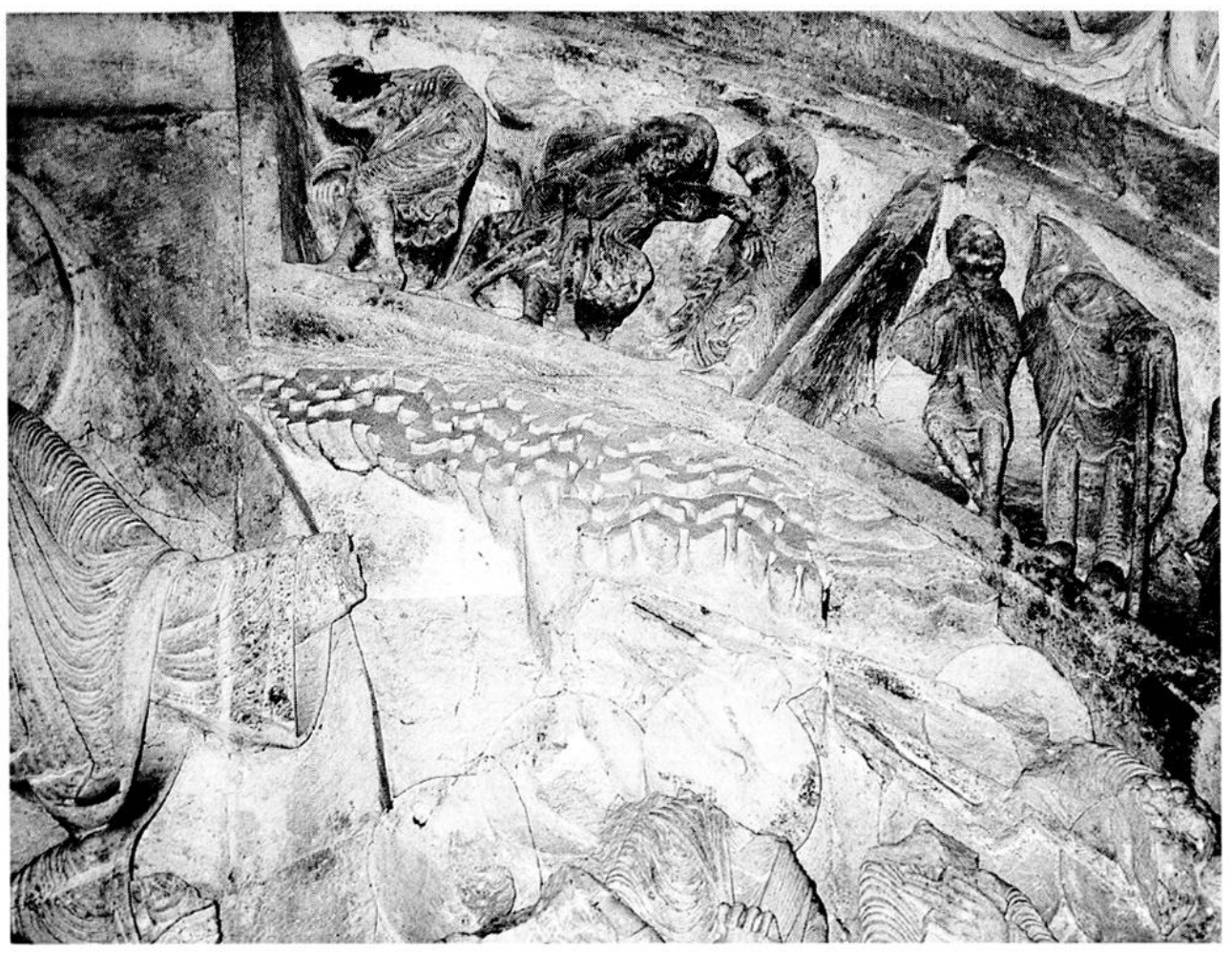

Fig. 3. - VÉthaY (Yonne). Tympan. Ondulations situées à la gauche du (hrist. 
le socle, ne laissent aucun doute à ce sujet ${ }^{34}$. L'on trouve donc, dans l'axe du portail, la superposition du Christ et de l'Agneau si fréquente dans l'iconographie de l'Apocalypse ${ }^{35}$. On verra plus loin le rôle précis joué par Jean-Baptiste et l'Agneau dans l'organisation générale du portail, mais on peut déjà supposer que cette disposition a été suggérée à la fois par l'Apocalypse et par ses représentations.

\section{L'arbre de vie et les apôtres.}

À la gauche du Christ, au milieu des nuées ou prenant la place de celles-ci. apparaît ce qui semble être les feuilles d'un arbre [fig. 3], et dans lesquelles Crosnier a voulu reconnaître l'arbre de vie de l'Apocalypse : In medio plateae ejus, et ex utraque parte fluminis lignum vitae, afferens fructus duodecim, per menses singulos reddens fructum suum, et folia ligni ad sanitatem gentium $(22,2)^{36}$. En fait, la nuée que l'on voit à gauche de la tête du Christ a sans doute possédé son équivalent à droite. Mais là, elle semble avoir été retaillée, et ce, uniquement sur une des dalles constituant le tympan, celle de droite ayant conservé son tracé primitif. Cette transformation ultérieure, mais sans doute antérieure à la pose de la dalle ${ }^{37}$. explique peut-être pourquoi, de près, ces ondulations ne ressemblent pas toujours à des feuilles; de loin, en revanche. l'effet est plus probant. L'identification de ces ondulations avec l'arbre de vie est donc possible, mais légitimement contestable ${ }^{38}$. Ce n'est que dans la mesure où elle s'accorde parfaitement avec l'interprétation proposée que je prendrai en considération l'analyse de Crosnier. tout en conservant à son égard une certaine réserve.

34. E. Viot.t.ET-1.F-Duc, Monographie de l'ancienne église abbatiale de Vézeliy. Paris. 1873, p. 17. a facilement reconstitué

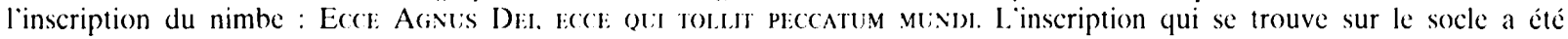

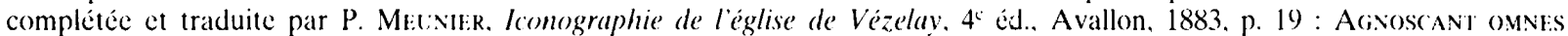

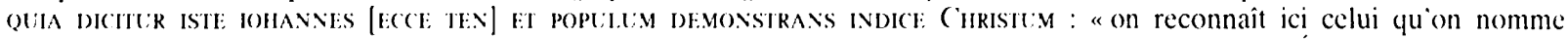
Jean. il retient le peuple et du doigt lui montre le ('hrist». F. SAli:T. La Madeleine de Vézeles. Étude iconnographique" par Jean Adhémar. Melun. 1948. p. 174. renseigné par un document darchives. rapporte que Viollet-le-Duc a complété la lacune par [ces (?) ketINfit]. Peter Diruer. Stil und Ikonographie der Kapitelle von Sainte-Madeleine, Vézelay |thèse

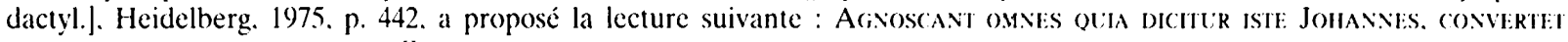
POPITITM DFMONSTRANS INDICF CHRISTLM.

35. X. BARRAL I AtTET. "L Liconographie de caractère synthétique et monumental inspirée de l'Apocalypse dans lart médiéval d'Occident (IX'-XIII" siècles)"; et P. K. KIFIN, "Les cycles de l'Apocalypse du haut moyen âge (IX"-XIII" s.)". dans Y. Christe. éd. I:Apocalypse de Jean. Genève. 1979, respectivement p. 135-186. avec les exemples de (ivate. fig. 34. et de la Bible de Roda, lig. 48, et p. 187-216, avec les exemples de Rignano Flaminio, fig. 10. et de la chapelle Saint-Michel d'Aiguilhe au Puy. fig. 15. Voir également F. VAx dFe Mil:k. L'Apocalypse dans lart. Anvers, 1978. À Sainte-Pudentienne. à Rome. l'Agneau était représenté dans l'abside sous le Christ trônant au milieu des apôtres et de la Jérusalem céleste. un schéma très proche de celui de Vézelay. Voir à ce sujet E. Dassman, "Das Apsismosaik von S. Pudenziana in Rom». Römische Quartalschrifı, 65, 1970, p. 67-81.

36. Crosnier, "Iconographic..." (voir n. 3), p. 227; lidée a été reprise par P. Mrisiler. lconographie... (voir n. 34). p. 23: - F. Sal.t. La Madeleine... (voir n. 34). p. 175: - J. Evans. "Liconographic clunisienne". dans $A$ Cluny (congrès scientifique. 1949), Dijon. 1950). p. 44-50), et en particulier p. 49; - M.-L. Thékes., $\dot{A}$ l'origine du décor... (voir n. 1), p. 281. Pour A. Fabre. "Liconographic... " (voir n. 3), p. 39. et Difmek. "Das Pfingstportal..." (voir n. 1). p. 86. ce sont des nuages, pour A. Katzenfldexbogex. "The Central Tympanon at Vézelay. Its Encyclopedic Meaning and Its Relation to the First Crusade". The Art Bulletin. XXVI/3. 1944. p. 141-151. et en particulier p. 142. ce sont des nuages aux formes tourmentées qu'il met en parallèle avec les livres fermés tenus par les apôtres de droite. et auxquels il attribue une valeur eschatologique : il y aurait de part et dautre du Christ un bon et un mauvais côté.

37. Salinier et Stratford), La sculpture... (voir n. 28), p. 76. n. 4. Pour Dikmik. "Das Plingstportal... " (voir n. 1). p. 86-87. la différence de traitement entre les deux blocs pourrait être due à un manque de temps. Il ajoute que cette différence devait être masquéc par la peinture qui rehaussait les ornements et les figures du portail. et dont Viollet-le-Duc atteste l'existence. L'utilisation de la peinture pour la nuée et d’autres parties du portail a été examinée par N. SIRATFORD. "Romanesque Sculpture in Burgundy. Reflections on Its Geography. on Patronage. on the Status of Sculpture and on the Working Methods of Sculptors". dans X. BARRal I Altet, éd.. Artistes, artisans, el production artistique au moven age (colloque international. (NRS. Université de Rennes II-Haute-Bretagne. 1983). III. Paris. 1990). p. 245.

38. Dit:uE. "Das Pfingstportal..." (voir n. 1). p. 86. fait remarquer que ees ondulations correspondent a la maniere conventionnelle de représenter la nuée. et cite plusieurs exemples empruntés à la sculpture de Vézelay : le tympan du portail sud. et deux chapiteaux de la nef $(21$ et 94$)$. Ces derniers correspondent bien à la nuée située à la droite du Christ du portail central. En revanche. ils ne ressemblent pas aux ondulations situées à sa gauche. 
Pour Haymon, l'arbre décrit dans l'Apocalypse correspond à celui qui se trouvait au paradis et, à ce titre. il est le Christ qui dispense la vie éternelle à ceux qui mangent son fruit. L'arbre de vie, c'est aussi la sagesse de Dieu ${ }^{39}$. Ces idées sont empruntées à Ambroise Autpert qui ajoute que si l'arbre est le Christ. il est aussi l'Église. alors que pour Haymon c'est la platea - la place - qui représente l'Église ${ }^{40}$. En revanche, dans son sermon sur la dédicace de l'église, il commente l'Évangile de Luc sur la bona arbor qui donne des bons fruits (Lc 6, 43), établissant ainsi une relation symbolique entre l'arbre et l'ecclesia ${ }^{41}$. L'image de l'arbre s'applique dès lors autant à l'édifice sacré qu'à la communauté des croyants. Il faut également rappeler qu'au début du Tractatus de dedicatione ecclesiae, l'auteur exploite aussi cette image de l'arbre, qu'il cmprunte pour sa part à Apocalypse 22. 2.

Cette assimilation de l'arbre à l'Église est évidente dans une ouvre dont l'interprétation est assurée par un texte. Il s`agit de la mosaïque absidiale de Saint-Clément à Rome : les rinceaux d'acanthes qui envahissent le cul-de-four sont à la fois l'Église et la vigne que la Loi dessèche et que la croix fait verdir. Cette idée est renforcée par la présence d'une croix au centre de la composition, qui est également un arbre de vie ${ }^{+2}$.

Il en va de même chez certains commentateurs de l'Apocalypse : pour saint Jérôme, les douze fruits que produit l'arbre sont les grâces que les apôtres ont reçues de la croix, et avec lesquelles ils rassasient, par la prédication, les peuples épuisés par la faim ${ }^{43}$. Pour Bède, la croix du Christ fructifie par le biais de l'enseignement des douze apôtres ${ }^{44}$.

À Vézelay, la croix a peut-être été inscrite dans le schéma général du portail. Le linteau en formerait le bras horizontal, et le pilier central la partie inférieure du bras vertical. Quant à la partic supéricure, elle serait suggérée par l'interruption des compartiments rayonnants. Ceux-ci ont le profil de voussoirs, sauf ceux qui flanquent le vide central, et dont la forme a été modifiée pour que les parois libres soient verticales. La position des bras et des mains du Christ évoquent au demeurant celle du crucifié. Un schéma semblable a été adopté à Moissac mais là, scul un tau a été tracé ${ }^{45}$. La composition du portail de Vézelay semble donc avoir été conçue de manière à pouvoir superposer le Christ, la croix et l'arbre de vic, et permettre ainsi de visualiser l'équivalence symbolique entre ces deux derniers ${ }^{46}$.

L'Apocalypse dit encore de l'arbre de vie qu'il fructifie douze fois pour que, chaque mois, il donne son fruit. Ces douze fruits peuvent évoquer différentes choses : l'enseignement des apôtres, les apôtres eux-mêmes ${ }^{47}$ ou les vertus qu'ils font naître chez les saints ${ }^{48}$. Cela peut être aussi une façon d'exprimer l'éternité ${ }^{49}$. Par conséquent, si l'arbre peut être le Christ, ses fruits peuvent

39. In Apoc. VII, 22. PL, 117. 1211 D-1212 A.

40. In Apoc. X. 22, 1-2. CCCM XXVII A. p. 836.

41. BakRÉ, n" H II 49. PL 118.741-746.

42. H. Totbert. "Le renouveau paléochrétien à Rome au début du $\mathrm{XII}^{\mathrm{e}} \mathrm{s}$.". dans Un art dirigé. Réforme grégorienne et iconographie. Paris. 1990, p. 239-310. et en particulier p. 270 et ss. qui donne encore l'exemple de San Pedro de Sorpe où un arbre est également une image de l'Église opposée ici à l'arbre sec de la Sýnagogue. ibid.. p. 65-89. Elle fait également remarquer que la fondation d’un monastère est comparée à la plantation d'un bon arbre. cf. ibid.. p. 74 . n. 26.

43. Commentarius in Apocalypsin (in Apoc.). édité avec la version antérieure de Victorin par I. Haussleiter. CSEL 49. p. 149. et plus récemment par M. Dilaky, SC 423. p. 128-129. Le commentaire de Victorin est mentionné dans linventaire de la bibliothèque de Cluny ( $\mathrm{n}^{\prime \prime}$ 352). cf. Delusle. Le cabinet des manuscrits... (voir n. 7), p. 472. Lidée a été reprise par Beates de Libiana. Beati in Apocalipsin libri duodecim (in Apoc.) XII. 3. éd. H. A. Sanders. Rome. 1930. p. 636.

44. Bìne. Explanatio Apocalypsis (Apoc.) III, 22, PL 93, 204 C. Ouvrage mentionné dans l'inventaire de la bibliothèque de Cluny (n" 266). cf. Dest.st... Le cabinet des manuscrits... (voir n. 7), p. 468.

45. P. Sксвіszi:wski. "Le trumeau et le linteau de Moissac : un cas du symbolisme médiéval ". Cahiers archéologiques. 40. 1992. p. $51-90$.

46. Sur la façade de Saint-Pierre d'Angoulême. un trone se divise en deux rameaux qui soutiennent la gloire dun Christ: Y. Cintsit. Les grands portails romans. Etude sur l'iconographie des théophanies romanes, Genève. 1969. p. 85.

47. Attpert, In Apoc. X. 22. 1-2. CCCM XXVII A. p. 836: - Haymox, In Apoc. VII. 22. PL 117. 1212 A-B:RtPERT DE DEtT\%. Commentaria in Apocalypsin (in Apoc.) XII. 22. PL 169. 1207 A. Les deux premiers commentaires ont déjà été cités par Marie-Louise Thérel. Á lorigine du décor... (voir n. 1). p. 281.

48. AtTPFir. ibid.

49. Primast. In Apoc. V. 22, 2-3, CCSL XCII, p. 300. Repris par Bè.df., Apoc. III, 22, PL 93, 204 B.C. 
être ses apôtres. De même. si le Christ représente l'année. les apôtres en sont les mois. et s'il symbolise le jour. les apôtres sont les heures ${ }^{50}$.

Cette image pourrait done se superposer à celle de la Pentecôte, ce qui n'a pas échappé à Rupert de Deutz. Pour lui en effet. les douze fruits portés par l'arbre rappellent que le Christ a "ordonné " ses apôtres en leur donnant le Saint-Esprit ${ }^{51}$. Qu'un auteur contemporain du portail ait fait ce rapprochement est essentiel dans cette démonstration. Cela laisse supposer que le concepteur. qu'il ait lu ou non ce commentaire. a pu faire le même raisonnement.

\section{Les peuples de la terre.}

La scène de la Pentecôte s'accompagne d'un catalogue exceptionnellement développé des peuples de la terre, dans lequel le concepteur a mêlé des représentations de races monstrueuses: cynocéphales, panotii ou panotéens, androgynes et vraisemblablement des nains et des géants ${ }^{52}$. Cette description se trouve à la fois dans les compartiments disposés en arc de cercle interrompu à son sommet [fig. 3], et sur le linteau. L'identification des peuples et des races monstrueuses a souvent été débattue, mais il est encore très difficile de les reconnaître tous avec certitude.

La partic gauche du linteau [fig. 4] a également fait l'objet de maintes discussions. On y a vu notamment le sacrifice d'un taureau et la procession qui l'accompagne ${ }^{53}$. La scène évoquerait dès lors les Gentils et peut-être plus précisément les Romains ${ }^{5+}$ : mais cette lecture a été contestée et d'autres interprétations ont été avancées. Plusicurs modèles et sources ont été invoqués pour expliquer le choix d'une telle scène ${ }^{55}$. Il faut toutefois constater que l'Apocalypse fournit également la description d'une procession semblable à celle de Vézelay: Et ambulabunt gentes in lumine ejus : et reges terrae afferent gloriam suam et honorem in illam /civitam] (21.24). Pour Bède, les rois sont ceux qui apportent toutes les richesses de leurs vertus par des louanges ${ }^{56}$. Autpert rapporte aussi ce passage aux cuuvres du temps présent : les nations et les rois sont les pèlerins qui marchent à la lumière de l'Agneau. Les rois de la terre sont ceux qui surent se rendre maîtres de leur corps et de l'agitation de leurs pensées. Il ajoute plus loin que ce sont aussi les

50. Actrikt. ibid.; - HaYmos, ibid.

51. RUPI:RT, in Apoc. XII. 22. PL 169. 1207 A.

52. Pour le quatrième compartiment en partant de la gauche. il sagit de toute évidence de cunocéphales. cf. SAIIIT. La Madeleine... (voir n. 34). p. 125-126 et 176. et non du mythe de ("ircé comme l'a affirmé ( $h$. Picari). "Le mythe de Circé au tympan du grand portail de Vézelay ». Bulletin momumental. 103. 1945. p. 213-229. Pour les cynocéphales, voir C. Licottetx. "Les cynocéphales. Étude d'une tradition tératologique de l'Antiquité au XII" s.". Cahiers de civilisation médiévale. XXIV. 1981. p. 117-128. Les panotéens ou panotii. ces êtres aux oreilles démesurément grandes. se trouvent à l'extrémité droite du linteau. of. Salrz, ibid. p. 128 et 177: - Fildoman. The Narthex Portal... (voir n. 1). p. 49. Pour SAlET. ibid., p. 125 et 175. ceux que saint Augustin appelle androgynes et qui sont également appelés siamois, se trouvent dans le troisième compartiment. Les nains ou pygmées se trouvent dans la partie droite du linteau. cf. FAbre. L icomographie... (voir n. 3), p. 41; - Sallit. ibid. p. 128 et 177. Au sujet de nains. voir (. Lecoutelx. Les nains et les elfes au moyen age. Paris, 1988. Pour G. Savoner, "Portail de labbaye de Vézelay. Interprétation du sujet du linteau et des chapiteaux de la porte centrale de la nef ". Revue de l'art chrétien, 15. 1904, p. $448-459$ et en particulier p. 455. ce sont des (onmains. Pour Fridman, ibid. p. 50. ce sont des enfants. Salfet. ibid., p. 128 et 177 . voit dans les géants les Macrobii de l’Inde, et dans les hommes au ne\% en groin de porc. les Éthiopiens.

53. Sur la partie gauche du linteau se succèdent. de gauche à droite. des archers. des hommes. dont certains ont les mains voilées par un pan de leur manteau. portant successivement un récipient contenant du raisin (?). un pain (?). un vasc. un poisson. un seau. une lance ou une longue pique (deux fois). une hache. et à nouveau une lance. Plusieurs figures ont au contraire les mains libres. Au premier plan. à droite. se tient un taureau. Pour J. AdHÉmak. Influences antiques dans l'art du moven âge français. Recherches sur les sources et les themes d'inspiration. Londres. 1937. p. 178-179: repris dans Salfit. La Madeleine... (voir n. 36). p. 128 et 177. et Cluny et Vézelay. L'oeuvre des sculpteurs. Paris. 1995. p. 104, il s'agit d'un sacrifice antique. Pour SANoNer. "Portail..." (voir n. 51). p. 453. ce sont les offrandes apportées par le peuple en vue de la croisade. Pour Fildoman. The Narthex Portal... (voir n. 1), p. 55-59. il sagit dune procession évoquant à la fois la remise de la dîme à labbaye de Vézelay. et le pélerinage au sanctuaire de la Madeleine.

54. Salit, La Madeleine... (voir n. 34). p. 128 et 177.

55. Pour Katzenemimbigix, "The (entral Tympanon..." (voir n. 36), p. 143, lidede de procession vient de deux passages d Isaïe : 49.12 et 55.5 .

56. In Apoc. III. 21. PI. 93, 203 D. 


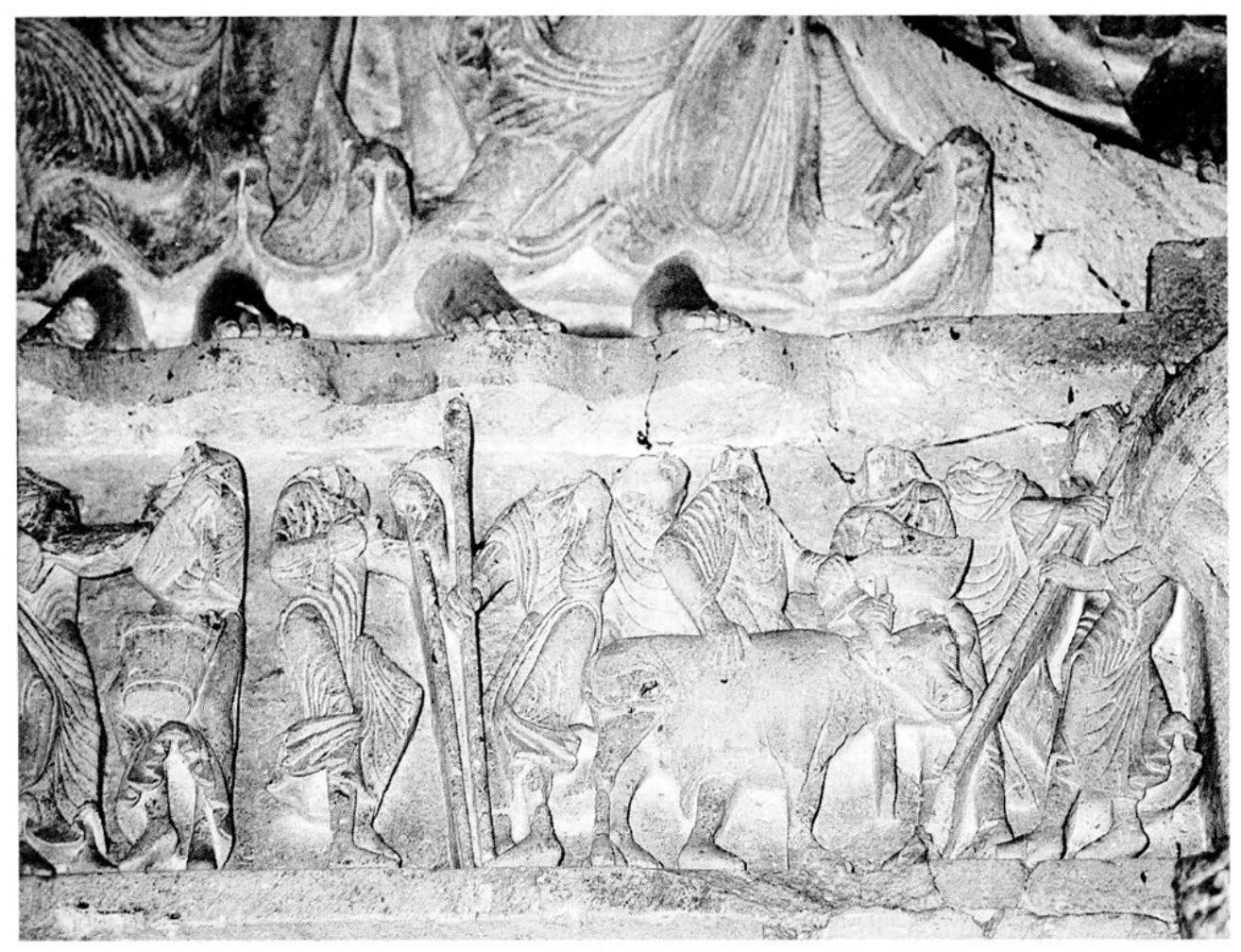

Fig. 4. - Vézelay (Yonne). Linteau. Fin de la procession avec le taureau. iCliché M. Angheben.)

Fïg. 5. - Véthlay (Yonne). Médaillons intermédiaires situés au-dessus du (hrist. (Cliche Paris, Caisse Vat. Monum. Histor., nég. 52 P 359.) 
prédicateurs - predicatores sanctos - parce qu'ils conduisent les fidèles vers la patrie éternelle ${ }^{57}$. Pour Haymon, les nations sont les saints qui marchent dans la lumière du Christ, les rois sont les justes ou encore les apôtres et les prédicateurs qui apportent gloire et honneur dans la Jérusalem céleste, c'est-à-dire à tous ceux qu'ils ont convertis par la prédication et l'enseignement ${ }^{58}$. Pour Rupert, les uns comme les autres sont les Gentils devenus les serviteurs de Dicu ${ }^{59}$.

La scène représenterait donc non pas un sacrifice païen, mais une procession dans laquelle chacun viendrait apporter un présent à l'Eglise : un produit de la campagne pour les uns, une arme pour les autres. Le geste du guerrier situé face à saint Pierre est, à cet égard, particulièrement éloquent : il pointe son épée vers le bas, indiquant peut-être, par ce geste, qu'il renonce à s'en servir ou qu'il met cette arme au service de l'apôtre et de l'institution qu'il représente. Certains participants semblent encourager leurs voisins à se hâter, leur indiquant. de l'index, le Christ du tympan. On pourrait donc considérer que toutes ces figures évoquent les nations et peut-être les rois. marchant dans la lumière du Christ et apportant gloire et honneur dans la Cité sainte ${ }^{60}$.

La présence des peuples de la terre est le prolongement logique de la scène centrale. C'est en effet dans les Actes (2,9-11) qu'ils sont énumérés après que les apôtres eurent reçu le don des langues. En revanche, les races monstrueuses ne sont pas mentionnées. Leur insertion au milicu des peuples peut facilement s'expliquer à partir de l'histoire de la tour de Babel et son commentaire par saint $\Lambda$ ugustin dans la Cité de Dieu. En cffet, la Pentecôte est souvent considérée comme le dénouement de cet épisode. L'envoi de l'Esprit-Saint a inversé le rôle des langues : avant cet épisode, elles divisaient; après lui, elles manifestent l'unité de l'Église ${ }^{61}$.

Il en va de même pour l'évêque d'Hippone qui explique que Babel et Babylone sont une seule et même ville fondée par le géant Nemrod, et dont le nom est "confusion" (16. 4). Ensuite. il évoque les soixante-douze nations et les langues encore plus nombreuses issues des trois fils de Noé et de la confusion des langues $(16,6)$. C'est alors qu'il pose le problème des races monstrueuses : descendent-elles d'Abraham, et par conséquent appartiennent-elles au genre humain? Autrement dit, faut-il les ajouter aux nations déjà citées? Saint Augustin ne donne pas de réponse définitive : à l'exception des antipodes dont il nie formellement l'existence, les races monstrueuses appartiennent bien à la descendance d'Adam, à condition que les récits qui ont été faits à leur sujet ne soient pas mensongers $(16,8-9)$.

Malgré leur caractère mitigé, ces réflexions sont sans doute à l'origine de l'intérêt porté par les auteurs du moyen âge aux êtres monstrueux ${ }^{62}$. Ce texte fondamental qu'est la Cité de Dieu a donc pu inspirer le concepteur du portail, soucicux de n'oublier aucune des races appelées à recevoir la grâce ${ }^{6.3}$. Saint Augustin ne cite toutefois pas les panotii, mais un ou plusieurs autres ouvrages ont pu compléter son catalogue ${ }^{64}$.

57. In Apoc. X. 21, 24, CCCM XXVII A. p. 828-829.

58. In Apoc. VII, 21, PL 117, 1209 (-D - 1210 A-B. Presque tous les personnages étant décapités, on ne peut pas savoir si certains étaient couronnés.

59. In Apoc. XII. 21. PL 169. 1204 A-C.

60. Dans cette perspective. I'on pourrait reconsidérer l'hypothèse rappelée à la note 53. et selon laquelle la procession de gauche serait liée au paiement de la dîme. On pourrait voir également dans cette scène. comme me le suggère Dominique Iogna-Prat, une préfiguration du sacrifice eucharistique dans le paganisme. Pierre le Vénérable utilise cet argument contre les pétrobrusiens pour montrer que. contrairement à leur opinion. la Cène doit être reproduite indéfiniment. Sans répétition. l’Église n’existe pas : les juifs ne sacrifiant plus et les musulmans ne sacrifiant pas. les chrétiens sont les seuls à perpétuer celle tradition des sacrifices antiques. Cest la mission historique de l'Église : sans cela. elle court à sa perte.

61. Cabí. La Pentecôte... (voir n. 12). 1965, p. 228-232 et 198: et "Pentecôte" (voir n. 12), col. 1032-1033.

62. C. Bolr.1ot, Les hommes monstrueux dans la littérature et l'iconograpinie [thèse dactyl.]. 1984: et C. Lecoltfetx. Les monstres dans la pensée médiévale européenne. Paris. 1993. p. 24.

63. Ce souci de noublier aucune race s'accorde bien avec ce que Dominique Iogna-Prat appelle la logique du tout ou rien chère à Pierre le Vénérable : le baptême pour tous ou pour personne. Cf. D. Iogiva-PRAt. "Ordonner et exclure". Clumy et la société chrétienne face à thérésie, au judaïsme et à l'lslam 1000-1150), Paris. 1998. p. 155-156.

64. Voir à ce sujet les suggestions de Salet. La Madeleine... (voir n. 36). p. 129. Salvi Alciasma (De Ciritate Dei 16. 8) donne lexemple réel d’un androgyne dont la partie supéricure était double et la partie inféricure simple. Quant aux géants. leur existence est antérieure à Thistoire de Babel. puisque c'est l'un d'entre eux. Nemrod. qui l'a fondée (ibid. 16.4). 
On retiendra que, pour cet auteur, les soixante-douze peuples de la terre et les races monstrueuses se sont divisés à la suite de la confusion des langues dans Babel-Babylone. Or, on l'a vu, c'est le même saint Augustin qui situe la fondation de la Jérusalem céleste le jour de la Pentecôte. L'opposition Babel-Église peut donc se ramener à celle qui voit s'affronter Babylone et la Jérusalem céleste. Bède le Vénérable résume cette idée en quelques mots dans son commentaire sur l'épisode de la Pentecôte (Actes 2) : "L'unité des langues que l'orgueil de Babylone avait brisée, l'humilité de l'Église la reconstitue " 65 .

Le catalogue des peuples de Vézelay serait donc une vision élargie des nations énumérées dans les Actes, divisées après l'épisode de Babel et ramenées dans l'unité de l'Église depuis que la grâce est descendue sur les apôtres ${ }^{66}$. C'est du reste ce qu'évoque la convergence des deux processions du linteau qui se dirigent vers les deux personnages en pied, saint Pierre et celui en qui on a voulu reconnaître saint Paul ${ }^{67}$.

Une autre particularité a souvent été relevée dans ce catalogue : plusieurs personnages montrent ostensiblement les signes d'une infirmité ou d'une douleur ${ }^{6 x}$. Cela pourrait s'expliquer simplement par le caractère dégénéré des races monstrueuses, mais des hommes, en apparence normaux, expriment également leur souffrance. On pourrait alors envisager que la douleur du corps reflète celle de l'âme, et que sa cause est le péché. Plusieurs passages scripturaires confortent cette idéc. Les Actes, notamment, relatent après le récit de la Pentecôte les miracles réalisés par les apôtres, en particulier la guérison d'un boiteux ${ }^{69}$. Saint Marc rapporte pour sa part qu'avant l'Ascension, le Christ envoyant ses disciples en mission leur prédit qu'ils imposeraient les mains aux malades et que ceux-ci seraient guéris. Et, de fait, après avoir été enlevé au ciel, le Seigneur travaillait avec ses disciples et confirmait leur parole en l'accompagnant de miracles (16,20).

Il est au demeurant significatif que, parmi les lectures qui étaient faites à Cluny durant la semaine qui suivait la Pentecôte, trois passages empruntés aux commentaires de Bède sur l'Évangile de saint Luc font référence à des guérisons opérées par le Christ ou par les apôtres ${ }^{70}$.

La même idée est encore présente dans l'Apocalypse. L'arbre de vie dont il a déjà été question est en effet pourvu de feuilles qui ont la vertu de soigner les nations $(22,2)^{71}$. Autpert voir dans ces feuilles, les prédicateurs, nés dans l'Église de l'enseignement des apôtres, et qui soignent les nations par l'exemple et la parole ${ }^{72}$. Haymon ne s'en éloigne guère lorsqu'il dit que les feuilles sont les disciples des apôtres qui obtiennent la santé des nations qu'ils instruisent par l'exemple ét l'enseignement, êt qu'ils amènent à la véritable santé de l'esprit ${ }^{73}$. Pour Rupert enfin, ce sont

65. Expositio Actum Apostolorum I1. 4. éd. M. L. W. LaIstrer. CCSL (XXI. p. 16. Ouvrage mentionné dans le catalogue de (luny ( $\mathrm{n}^{\circ}$ 260): cf. Detlssil. Le cabinet des manuscrits... (voir $\mathrm{n}$. 7). p. 467. Même idée chez Trraves RuFinis. Orationum Gregorii Nazianzeni novem interpretatio IV. 16. éd. A. EN(illbkl:cht. CSEL 46. p. 161: ce texte élait lu à Cluny le samedi suivant la Pentecôte, ef. $L T$ 76.5: CCM X. p. 119.

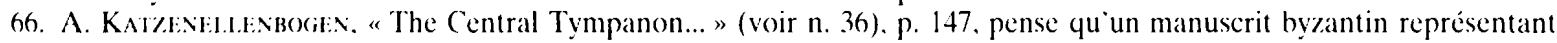
l'histoire de la tour de Babel a pu fournir un modele à Vézelay.

67. On a longtemps pensé que la figure qui flanque saint Pierre était sainte Marie-Madeleine : VIol.1.1:I-1.F-D):C. Monographie... (voir n. 34), p. 16: - Mrtwar. Iconographie... (voir n. 34). p. 19-20). etc. SAlFi. La Madeleine... (voir n. 36).

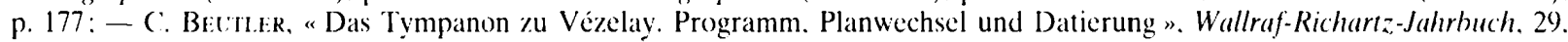
1967. p. 7-30). et en particulier p. 10): et Thíkel. Á lorigine du décor... (voir n. 1). p. 282. y ont vu la figure de saint Paul. Lhypothèse me paraît daautant plus solide que. sur l'ébrasement de droite. c'est saint Paul qui semble figurer à côté de saint Pierre [fig. 6].

68. Compartiments 3. 4. 5 et 6. et lenfant du couple panotéen sur la partie droite du linteau. Katzintillexbogen. "The central Tympanon..." (voir n. 36). p. 144-145. a tenté de déterminer avec précision quels étaient les maux dont ils souffraient.

69. Actes 3. A Vé\%clay, plusieurs personnes boitent.

70. R. Finx. Homéliaires patristiques latins. Recueil déundes de manuscrits médiévaux. Paris. 1994. p. 106. temporal n" 117-119. Bìdo. In Lucae evangelium expositio (In Luc.) IV. 38-42. éd. D. Hersi. CCSL CXX. p. 111-113 : ce passage commente la guérison de la belle-mere de Pierre et les nombreux miracles qui ont suivi: une autre lecture. ibid. V. 18-25. p. 119-122. se rapporte à la guérison d'un paralytique: la troisieme. ibid. VIII. 1-6. p. 194-196, fait référencé aux guérisons opérées par les apótres. lorsque le (hrist les envoya en mission pour la premiere fois.

71. (e rapprochement a déjà été fait par J. Fvass. "L.iconographie... " (voir n. 36). p. 49.

72. In Apor. X. 22. 1-2. CCC.M XXVII A. p. 836.

73. In Apoc. VII. 22. PL. 117. 1212 B. Pour Bruno de Segni. Expositio in Apocalypsim rin Apoc.) VII. 22. PI. 165. 7.30 (. larbre contient les deux Testaments. 
les paroles de l'Évangile : les nations en les recevant acquerront la santé éternelle du corps et de l'âme ${ }^{74}$. Ici. la guérison du corps est done bien liée à celle de l'âme.

Si le recours à l'Apocalypse et à ses commentaires n'est pas indispensable pour comprendre l'infirmité de certains personnages, on constatera qu'une fois de plus, ces textes se superposent parfaitement avec certains motifs du portail et le thème de la Pentecôte. Au moment où l'Esprit-Saint descendit sur les apôtres, la Jérusalem céleste a vu le jour pour faire contrepoids à Babel-Babylone, la cité de la confusion. Cette dernière ne sera anéantie qu'à la fin des temps, mais désormais toutes les nations. y compris les races monstrucuses, sont susceptibles d'être touchées par la grâce. Dès lors, ce sont les apôtres et leurs disciples qui feront des miracles et enseigneront, de sorte qu'ils guériront tant les corps que les âmes. Les apôtres sont les fruits issus du bois de la croix-arbre de vie, et leurs disciples en sont les feuilles destinées à guérir les nations par l'exemple et par la prédication.

C'est du reste l'apôtre Pierre, peut-ĉtre accompagné de saint Paul. qui accueille les peuples de la terre au centre du linteau. On peut les voir comme les représentants de l'Église de Rome ou encore de celle de Vézelay, qui, dès sa naissance. fut placée sous la protection des deux saints ${ }^{75}$.

L“insistance sur la figure de saint Pierre - représenté en trois endroits différents - a suscité plusicurs hypothèses sur la portée politique du programme iconographique : affirmation du pouvoir de l'abbaye face à ses ennemis, rattachement à l'Église de Rome, etc. ${ }^{7 h}$. Il faut toutefois observer que chez saint Jean, l'envoi du Saint-Esprit est immédiatement suivi par la transmission aux apôtres du pouvoir de remettre les péchés. Rupert, lorsqu'il commente ce passage, rappelle l'investiture de Pierre rapportée par saint Matthieu : Et tibi dabo claves regni caelorum... (Mt. 16, 19) ${ }^{77}$. Ce rôle de chef de l'Église, saint Pierre l'assuma dès le jour de la Pentecôte lorsqu'il prit la parole au nom de tous les apôtres (Actes 2). Il est donc logique que, sur le tympan, il se trouve à la droite du Christ, portant les clefs que celui-ci lui a remises. Ces remarques n'impliquent pas qu'il n'y ait pas eu. dans ce choix iconographique, une volonté de faire passer un message lié au pouvoir temporel et spirituel de l'abbaye, mais l'hypothèse est difficile à prouver, dans la mesure où l'importance de Pierre. lors de la Pentecôte. est largement justifiée par les textes cités, et d'autres encore.

\section{Le zodiaque et les quatre médaillons intermédiaires.}

L'association d’un zodiaque et des travaux des mois à une représentation de la Pentecôte peut difficilement se justifier par une référence aux récits scripturaires de cet événement ${ }^{78}$. En revanche, l'Apocalypse en fournit une explication à la fois simple et respectueuse du programme iconographique. En effet, il y est dit que l'arbre de vie fructifie douze fois pour que chaque mois il donne son fruit ${ }^{79}$. Si, pour certains exégètes, les douze mois sont les douze apôtres, pour d’autres. c'est une façon d'exprimer l'éternité ${ }^{80}$. Les médaillons du zodiaque et les travaux des mois seraient donc la représentation de la continuité de la vie qui anime l’arbre planté au milieu de la Jérusalem céleste.

74. In Apos. X11. 22. 13., 169, 12107 B.

75. (harte 1 de Vérelay (858-859). éd. R. B. C. Hoycisss, dans Momumenta Vizeliacensia. Téxtes relatifs à l'histoire de l'abbaye de Vézelay, CCCM XIII. p. 243-393, et en particulier p. 245. lignes 57-58. ('ette protection particulière des saints Pierre et Paul est régulièrement rappelée dans la chronique : ibid.. p. 395-610.

76. Fildomax. The Narthex Portal... (voir n. 1). p. 94-95.

77. In Ioh. XIV. 20. 22-23. CCCM IX. p. 772. Pour Bruno de Segni. in Apoc. VII. 21. PL. 165, 721 B-C. ce sont les apôtres en général qui ont reçu du Seigneur les clés du rovaume céleste. et le pouvoir de lier el de délier.

78. Pour Sales. La Madeleine... (voir n. 34). p. 129-130) : cest le "symbole de la Durée au sein de laquelle se meuvent lactivité dés hommes et la vie méme de l'Église...".

79. Evans. "L.̈iconographie..." (voir n. 36). p. 49. a déjà formulé cette idéce.

80. Primasi, in Apos. V. 22. 2-3. CCSI. X(II. p. 300): - Ripert. in Apoc. XII. 22. Pl. 169. 1207 B. 
À Autun, un ensemble très proche de celui de Vézelay encadre un Jugement dernier ${ }^{81}$. La représentation d'un zodiaque n'est donc pas obligatoirement liée à l'arbre de vie. En revanche, on a pu utiliser ce thème très ancien pour renforcer l'image de l'arbre éternellement vert. À Saint-Clément, par exemple, les rinceaux de la vigne-Église sont accompagnés de scènes pastorales et de basse-cour ${ }^{82}$. Sur la mosaïque de la cathédrale d’Otrante. l’analogie avec le portail de Vézelay est encore plus marquée : une grande partie du pavement du vaisseau central est divisée en deux par un arbre qui s'épanouit en une série de médaillons abritant un zodiaque et les travaux des mois ${ }^{83}$.

Dans l'axe du portail, le cycle du zodiaque est interrompu par trois médaillons où sont représentés une sirène, un chien et un homme, ces deux dernières figures étant enroulées de manière à épouser la forme du cadre [fig. 5]. Un quatrième médaillon très exigu est venu combler l'espace qui restait entre le signe du Cancer et le chien. Il a été coupé dans sa partie droite, comme si. durant les travaux, l'on s’était aperçu que le bloc ne pourrait pas šintégrer dans la voussure. En revanche, la grue qui y figurc s'adapte parfaitement à ce cadre.

C'est encore une fois l'Apocalypse qui pourrait donner la clef de l'iconographie de ces médaillons. En effet, après avoir fait la description de la Jérusalem céleste. lauteur de la vision vitupère ceux qui ne sont pas dignes d'y entrer : Foris canes, et venefici, et impudici, et homicidae, et idolis servientes, et omnis qui amat et facit mendacium $(22,15)$. Il n’y a que quatre médaillons pour six sortes de pécheurs, mais on comprendra que, faute de place. on se soit contenté d'une liste incomplète. En revanche, la présence d'un chien sur la voussure permet de soutenir l'idéc d'un lien avec l'Apocalypse. Haymon fait de ces chiens les juifs, les hérétiques et les autres incrédules qui aboient contre l'Église ${ }^{84}$. Pour Rupert, ce sont les sots qui retournent à la déraison comme le chien retourne à ses vomissures (Prov. 26, 11; Petr. 2, 22) ${ }^{85}$. Le proverbre qu'il cite est un poncif de la littérature ecclésiastique dont on se sert notamment pour désigner les hérétiques. II n'empêche que le chien de Vézelay qui se retourne sur lui-même évoque peut-être la folie. mais surtout le proverbe cité par Rupert et dont l'idée pouvait difficilement être exprimée différemment. Il faut noter en outre que Pierre le Vénérable, dans son traité contre les juifs, compare aussi ces derniers à des chiens ${ }^{86}$.

La sirène est généralement liéc au péché de luxure ${ }^{87}$. Elle pourrait représenter ici les impudici. qui sont ceux qui pèchent contre la chasteté ${ }^{88}$. L'homme qui se renverse en arrière pour saisir ses chevilles est sans doute, comme on l'a proposé, un acrobate ${ }^{80}$. Il correspondrait alors à ceux qui aiment et pratiquent le mensonge. Le jongleur est en effet celui que l'Église rejette de la société des hommes à cause de ses gestes excessifs, mais surtout à cause de sa parole qui est

81. P. MAN:. "Comparaison des thèmes iconographiques des calendriers monumentaux el enluminés en France aux $\mathrm{XII}^{\mathrm{C}}$ et XIII ${ }^{\circ}$ s. ». Cahtiers de civilisation médiévale, XXIX. 1986. p. 257-264. et en particulier p. 261.

82. H. Totbr:RI. "Le renouveau paléochrétien à Rome au début du XII" s. ». dans Un art dirigé... (voir n. 42). p. $286-292$.

83. C.A. Wit.tinsfix. L'enigma di Otranto. Il mosaico pavimentale del presbitero Pantaleone nella cattedrale. Lecee. 1980. p. 123 et ss. L'auteur pense que les travaux des mois seraient une évocation de la conséquence du péché originel représenté a la croisée du transept. Dans ce cas. l'analogie avec Vézelay serait surtout formelle. mais il est possible aussi qu’à Otrante ce sens se soit superposé à celui que je propose pour le portail de Vézelay. à savoir celui de laarbre donnant ses fruits durant les douze mois de lannée.

84. In Apoc. VI. 22. PL. 117. $121 \times$ B.

85. In Apoc. XII. 22. PL. 169. 1212 A.

86. Adiersus Indaeorum inveteratum duritiem. ed. Y. FRIEDMAN. CCCM I.VIII. Je remercie D. Iogna-Prat de mavoir signalé cette référence.

87. D. JaLABERT. "De lart oriental antique a laart roman : recherches sur la faune et la flore romanes: Il. Les sirenes". Bulletin monumental. X( V. 1936. p. 432-471: - E. Fikal. "La queue de poisson des sirènes". Romania. LXXIV. 1953. p. 433-507: - (). Torchiffe-Mriver. "De quand date la sirene-poisson?". Bulletin de lasseciation Guillaume Budé. XXI. 1962. p. 450-459: - M. VIt:11.ARI)-TRoltkot Rol1. "Sirènes-poissons carolingiennes". Cahiers archéologiques. XIX. 1969. p. 61-82: - J. L1:11:Rco. "Sirènes-poissons romanes". Revue belge d'archéologie et dhistoire

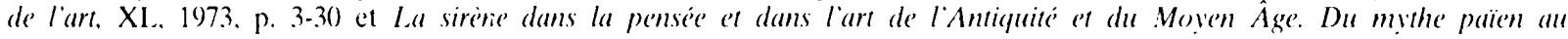
simbole chrétien. Bruxelles. 1997.

88. Harmos. in Apoc. VII. 22. Pi. 117. 1218 B.

89. SArfir. La Madeleine... (voir n. 34). p. 178. 
mauvaise et mensongère ${ }^{\%}$. La grue ou ibis évoquerait enfin les empoisonneurs - venefici dans la mesure où. se nourrissant de charognes. cet oiseau était considéré comme impur et donc impropre à la consommation "I.

Les quatre médaillons seraient done une sorte de catalogue des exclus de la société. telle qu'elle est définic par l'Église : les juifs et les hérétiques, les prostituées ou du moins celles qui se comportent comme elles. les jongleurs et les empoisonneurs. Ces pécheurs qui s'obstinent à demeurer dans l'erreur resteront à l'extérieur de la Jérusalem céleste, comme les damnés à qui le Juge dira Discedite a me maledicti (Mat. 25, 41) ${ }^{92}$. Cela rappelle la pensée de Pierre le Vénérable qui rattache les erreurs des musulmans et des juifs au péché de luxure : les juifs sont englués dans la chair et l'Islam est une religion de luxurieux. L'abbé de Cluny construit ainsi une image antithétique du moine angélique, opposé à l'exclu qui est automatiquement qualifié de fornicateur ${ }^{13}$.

Si le rapprochement entre les quatre médaillons de la voussure et l'Apocalypse est plus que vraisemblable. il est toutefois étonnant que ces images aient été placées dans la partie la plus élevéc du portail et dans le prolongement de l’axe de symétrie occupé par le Christ et Jean-Baptiste. On pourrait penser qu'un licu plus marginal eût mieux convenu à un tel sujet. Cependant, même si l'on conteste leur sens précis. la nature des figures et leur attitude attestent qu'elles sont connotées négativement. L'apparente incongruité de leur emplacement doit done être mise sur le compte du concepteur. soit qu'il n’en ait pas eu conscience, soit qu'il n'ait pas trouvé de meilleure solution ${ }^{94}$.

\section{Le fleuve d'eau vive et saint Jean-Baptiste.}

Et langelus] ostendit mihi fluvium aquae vitae, splendidum tanquam crystallum, procedentem de sede Dei et Agni (22.1) ${ }^{95}$. C"est sans doute ce que représentent les ondulations dans la partie inféricure du tympan. sous le trône [fig. 4]. On pourrait difficilement interpréter différemment leur présence aux pieds des apôtres qui, pour la Pentecôte comme pour la Mission, se tenaient sur la terre ferme et non dans les cieux ou dans les airs.

90. E. Faral. Les jongleurs en France au moven age. Paris. 1910. el en particulier p. 25-43: - (. (Casagikand): el S. Viccrito. "(leres et jongleurs dans la société médiévale (XI" et XIII" s.)". Annales E.S.C.. 34. 1979. p. 91.3-928.

91. Je remercie Alain Dierkens de mavoir suggéré cette interprétation. Les particularités de l'ibis sont décrites dans les bestiaires. Voir par exemple la version B. cf. F. J. Carmody. Physiologus latimus. Éditions préliminaires, versio B. Paris, 1939. p. 27-29. On peut également citer le bestiaire de Pierre Damien. plus proche dans le temps du portail de Vézelay

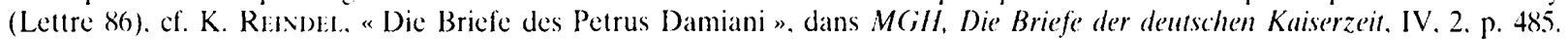

92. HAYMox. in Apoc. VII. 22. PL. 117. 1218 C. $^{\circ}$

93. Cette idée mà été communiquée par Dominique logna-Prat.

94. Pour ('. Bttılik. "Das Tympanon zu Vézclay.... (voir n. 67). p. 19. les trois médaillons intermédiaires auraient été ajoutés. en même temps que le Christ et le linteau actuel. lors deune seconde campagne. I.e premier projet naurait donc pas inclus le ('hrist. De plus. l'insertion des trois médaillons aurait impliqué que l'on coupe le médaillon où figure loiseau. (celte reconstitution a été réfutée par Dırmik. "Das Pfingstportal..." (voir n. 1). p. 91: et ('. E. Akмı. Masons and Sculptors... (voir n. 28). p. 182-186. Pour ce dernier. les trois médaillons auraient été ajoutés lors d'une troisième campagne. en mêne temps yue les apotres du tympan et les compartiments en demi-cercle. Mais dans sa reconstitution des étapes successives. ( C. E. Armi situe le projet dagrandissement du portail lors de la deuxieme campagne qui comprend le pilier central. les apôtres des ébrasements. le linteau. la plupart des médaillons et le (hrist. Il faut signaler que le médaillon incomplet se trouve sur un bloc où est représenté un des signes du zodiaque : le (ancer. Il en résulte que. quelles que furent les étapes de la construction du portail. un sujet différent devait. dés le début des travaux. s̈intercaler entre les médaillons du zodiaque.

95. ("kosille. "Iconographic..." (voir n. 3). p. 227: - Mrivite. Iconographie... (voir n. 34). p. 23: - SAlJi. La Madeleine... (voir n. 36). p. 175: -- Frass. Liconographie... (voir n. 36). p. 49 : pour cux. cette cau se trouve en haut.

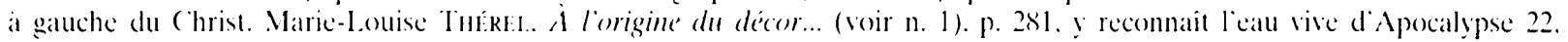
2. comme sumbole des eaux baptismales. Cette nuée pourrait simplement indiquer que le Christ est au ciel quand il envoic le Paraclet. 
Ce passage de l'Apocalypse est interprété de différentes manières, mais liidée la plus récurrente est que le flcuve représente le baptême ou les fruits qu'apporte ce sacrement ${ }^{\text {\% }}$. À Vézelay, cette idée semble s`être matérialisée puisque sous le fleuve est représenté Jcan-Baptiste [fig. 6].

Le fleuve d'eau vive est comparé par Rupert au Paraclet. le Saint-Esprit, dont la venue fut annoncée par le Christ et qui procède du Père. L'eau coule du trône de Dieu et de l'Agneau. de même qu'il est dit dans le symbole que l'Esprit-Saint procède du Père et du Fils ${ }^{97}$. Le lien entre le* sacrement du baptême et la Pentecôte est du reste une évidence puisque la réception de l'Esprit-Saint est décrite dans les Actes comme étant un baptême : ... Ioannes quidem baptizavit aqua, vos autem baptizabimini in Spiritu Sancto non post multos hos dies $(1,5)^{98}$. Les commentaires sur la Pentecôte vont en général dans ce sens ${ }^{99}$. La liturgie est encore plus claire à cet égard. puisque c'était exclusivement à Pâques ou à la Pentecôte que l'on administrait ce sacrement ${ }^{100}$.

Les ondulations placées à la base du tympan établissent donc un lien sémantique et visuel entre la scène de la Pentecôte et la figure de Jean-Baptiste.

Les commentaires de ce passage de l'Apocalypse permettent de mettre en lumière d'autres aspects du portail. Pour Autpert. l'Église est, à l'instar du Paradis, irriguée par le fleuve de la prédication ${ }^{101}$. Il en va de même pour Haymon qui ajoute que le fleuve représente l'enseignement de l'Ancien et du Nouveau Testament ${ }^{102}$. Ce thème de la prédication est omniprésent autour des ondes et de Jean-Baptiste : les apôtres du tympan tiennent un livre qui est ouvert à la droite du Christ et fermé à sa gauche; sur le linteau, les figures de saint Pierre et saint Paul (?). qui accueillent les nations, passent devant le fleuve; enfin, les apôtres des ébrasements et du pilier central s'adressent à leur voisin ou au fidèle qui franchit le seuil de la porte.

Il a été dit que l'arbre, comme le fleuve, peut représenter l'Ancien et le Nouveau Testament. C'est peut-être ce qu'évoquent les livres fermés et ouverts, à savoir la vérité voilée d'un côté, dévoilée de l'autre. Haymon précise bien que la prédication correspond à l'enseignement des deux Testaments. Cet enseignement est un, mais il est prononcé par plusicurs et parvient aux oreilles de nombreux auditeurs ${ }^{103}$.

Cela rappelle au demeurant qu'après la réception du don des langues, saint Pierre se mit à parler à la foule du Christ et de son message, tout en citant de nombreux passages de l'Ancien Testament (Actes 2, 14-36). Cette préoccupation d'inclure l'enseignement vétérotestamentaire dans celui de l'Église se retrouve aussi chez Pierre le Vénérable, lorsqu'il exhorte les pétrobrusiens à reconnaître la totalité des livres de la Bible, y compris ceux de l'Ancien Testament ${ }^{104}$.

\section{Les apôtres des ébrasements et du pilier central.}

Dans sa description de la Jérusalem céleste. l'auteur de l’Apocalypse décrit les douze portes disposées par trois dans les quatre directions de l'espace (21.12-13). En général. les exégètes y ont vu une image des apôtres et, à travers cux. des prédicateurs. par lesquels on accède à

96. Pour Jírôme, in Apoc. XXI. 1, CSEL 49. p. 149. le fleuve montre que sécoule la grâce de la naissance spirituelle: pour Primast. in Apoc. V. 22. 1-2. CCSL XCII, p. 299. il sagit des fruits quapporte la célébration du baptême. Bi:De. Apoc. III. 22. Pl. 93. 204 A. reprend textuellement lidée de Primase. Pour Atorplest. in Apoc. X. 22. 1-2. CCCM XXVII A. p. 835-836. le fleuve rend resplendissant ceux quil vivifie en les conduisant a lieau du baptéme: - Harmos. in Apoc. VII. 22. PL. 117. 1211 B. reprend les mots d'Autpert.

97. In Apoc. XII. 22. PL 169. 1206 ('-D.

98. Fillomax. The Narthex Portal... (voir n. 1), p. 120): pour elle. Jean-Baptiste est pris ici comme modele de vie contemplative et les inscriptions soulignent plutôt son rôle de précurseur.

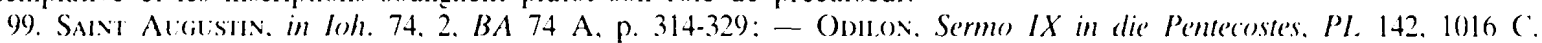

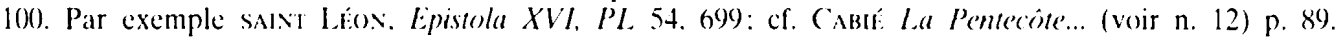

101. In Apoc. X. 22. 1-2. CCCM XXVII A. p. 835 .

102. In Apoc. VII. 22. PL. 117. 1211 B. Méme idée chè Brovo de Segivi. in Apos. VII. 22. PL 165. $730 \mathrm{~A}$.

103. Ibid.. 1211 B-C. Katravilimbocix, "The (entral Tympanon..." (voir n. 36). p. 142. interprete les livres ouverts et fermés daprès saint Jérome : les apôtres cachent le Sauveur a ceux qui ne croient fas en lui.

104. Contra Petrobrusianos hereticos, 14-88. éd. J. Fiakss. CCCM X. p. 15-55. 
l'Église ${ }^{105}$ : ce sont eux en effet qui ouvrent la porte de l'Église à toutes les nations ${ }^{106}$ ou qui, en prêchant. nous ouvrent le royaume de Dieu ${ }^{107}$. Voici ce qu'en dit Haymon qui se démarque ici d'Autpert : "Par douze portes, on comprend les douze apôtres, et par les douze apôtres, tout l'ordre des docteurs par le ministère desquels nous entrons dans l'Église. Ceux-ci en effet nous baptisent, et en enscignant, par la foi, nous introduisent par les portes de l'Église " ${ }^{108}$.

La confrontation du commentaire d'Haymon avec le portail de Vézclay est saisissante : situés dans l'embrasure, les apôtres [fig. 7] s'identifient aisément aux portes, mais surtout, c'est là que sont rassemblées les figures liées à la prédication et au baptême par l'intermédiaire desquels on entre dans l'Église-Jérusalem céleste. Les apôtres du centre, exhibant l'un un livre, l'autre un phylactère, évoquent selon toute vraisemblance l'enseignement ou la prédication. Il est possible que le personnage tenant un phylactère soit un prophète. Il est d'ailleurs situé à la gauche du Christ. rappelant peut-être, comme les apôtres du tympan aux livres fermés, que l'enseignement de l'Église intègre aussi l'Ancien Testament. Comme ces mêmes apôtres, il porte un vêtement qui n'est pas agité par le souffle qui anime les draperies des apôtres de l'embrasure et ceux qui, au tympan. se tiennent à la droite du Christ.

Les autres personnages des ébrasements et du pilier central semblent plutôt discuter entre cux, à moins qu'ils ne s'adressent directement au fidèle mais, là encore, l'objet de leur animation réside dans la parole inscritc dans les livres qu'ils portent ${ }^{109}$. Quant au baptême, c'est littéralement par lui que l'on entre dans l'Église, puisqu'il est matérialisé par la figure de Jean-Baptiste.

Une disposition semblable se trouve à Moissac où deux apôtres, saint Pierre et saint Paul, et deux prophètes sont sculptés sur les alettes et au pilier central. Or, pour Peter Klcin, le tympan montre une théophanie atemporelle et l'ensemble du portail une image de l'Église-Jérusalem céleste ${ }^{110}$. Comme à Vézelay, les apôtres, accompagnés ici de prophètes, seraient à la fois les portes et ceux qui ouvrent l'accès à l'église. À Ripoll, saint Pierre et saint Paul figurent sur les ébrasements du portail. Ici, une inscription gravée sur le livre porté par le premier permet de confirmer sa fonction : "Pierre ouvre le chemin et le peuple monte vers les étoiles" ${ }^{11}$. Il en va de même à Saint-Trophime d'Arles : saint Pierre accucille le fidèle sur la paroi de gauche du porche avec ces paroles inscrites sur le livre qu'il exhibe : "Pierre conduit au ciel ceux dont les péchés ont été remis ${ }^{112}$.

\section{Les chapiteaux.}

Il convient de terminer cet examen détaillé par les quatre chapiteaux qui seront abordés en partant de la gauche.

\section{a) La piscine probatique.}

On doit à Peter Diemer d'avoir découvert le sens de ce chapiteau. Il représente la guérison du paralytique près de la piscine de Betsaïda (Jn 5, 1-9). Le Christ est absent de la scène, mais le

105. HAYMON. "in Apoc. VII. 21. PL, 117. 1199 A

106. Bì:DF. Apoc. III. 21. PL 93. 196 A.

107. Riplekt. in Apoc. XII. 21. Pl 169, 1196 B. Pour Bfatts de Lifbana, in Apoc. XII. 2. éd. Sanders (voir n. 43). p. 625. les douze portes sont les apôtres, et les noms des douze tribus d'Isrä̈l sont les douze prophètes.

108. In Apoc. VII. 21, PL 117. 1198 B. el aussi 1210 C. Pour AltPert, in Apoc. X. 21, 12. CCCM XXVII A. p. 800. ce sont les prédicateurs et les pasteurs de l'Église.

109. SAlEt. La Madeleine... (voir n. 34). p. 174

110. P. KiriN, "Programmes eschatologiques. fonction et réception historiques des portails : Moissac - Beaulieu Saint-Denis". Cahiers de civilisation médiévale. 33. 199). p. 32()-330. L'Isä̈e de Souillac a sans doute joué la même fonction.

111. J. AINaIT) de LASARIE. Catalogne romame. La-Pierre-qui-Vire. 1994. p. 129: PETRUS ITER PANDIT F.T PLEBS AD SIDERA SCANDIT:

112. J.-M. Rotolitit. Provence romane. I : La Provence rhodanienne. La-Pierre-qui-Vire. 1974. p. 281-282: (RIMINIBLS DE:MPTIS RESERAT PETRUS ASIRA REDEMPTIS 


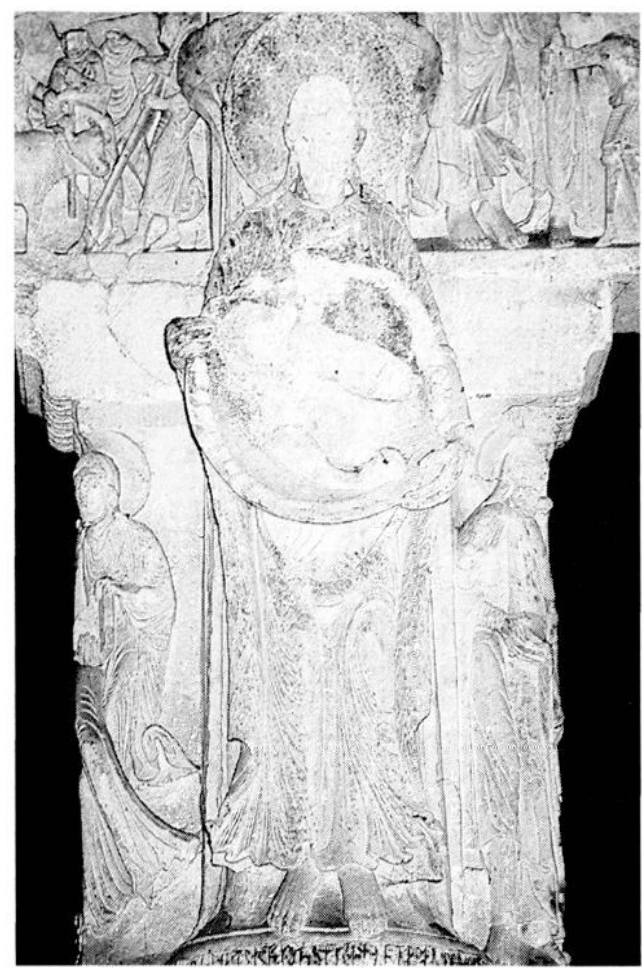

Fig. 6. - Vé:FitAY (Yonne). Pilier central. Figure de saint Jean-Baptiste.

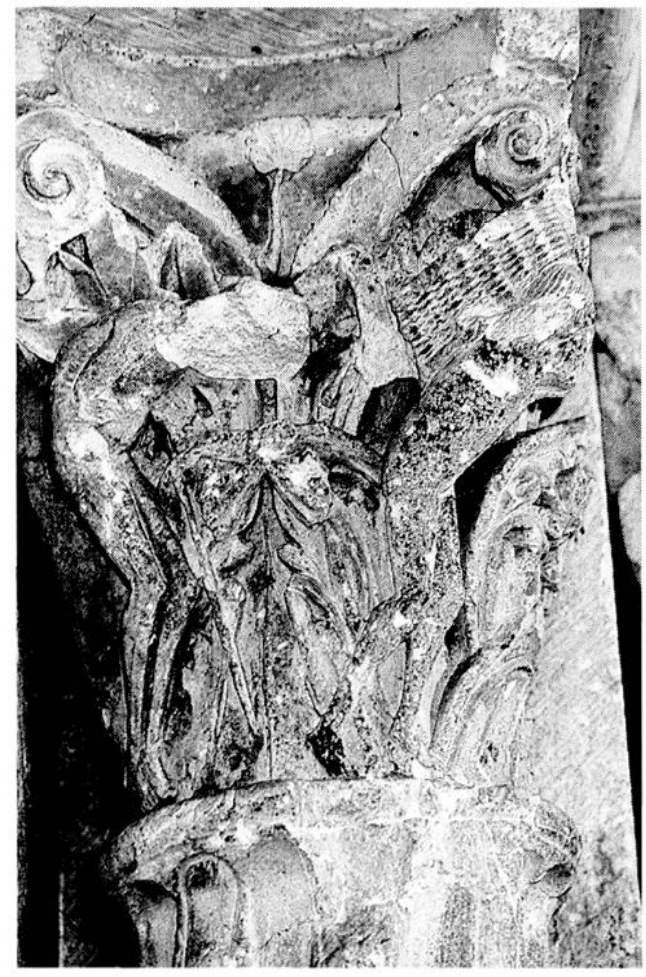

Fig. 8. - Vézzitay (Yonne). Ébrasement de gauche. chapiteau de gauche (inv. Salet "nef II "). Un paralytique portant son lit et sans doute un deuxième paralytique guéri.

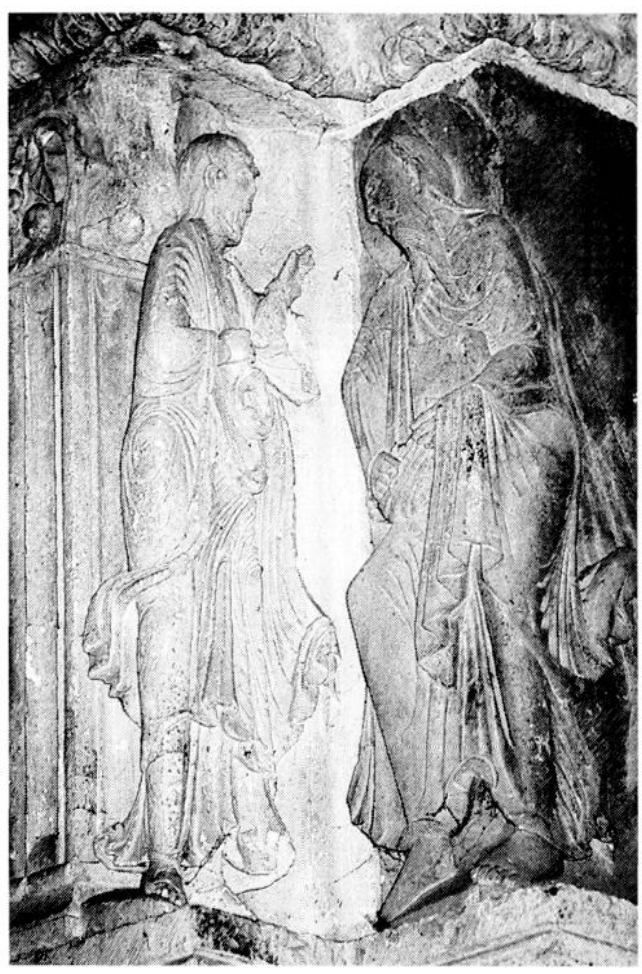

Fig. 7. - Vízli.ay (Yonne). Ébrasement de droite. Saint Pierre et sans doute saint Paul.

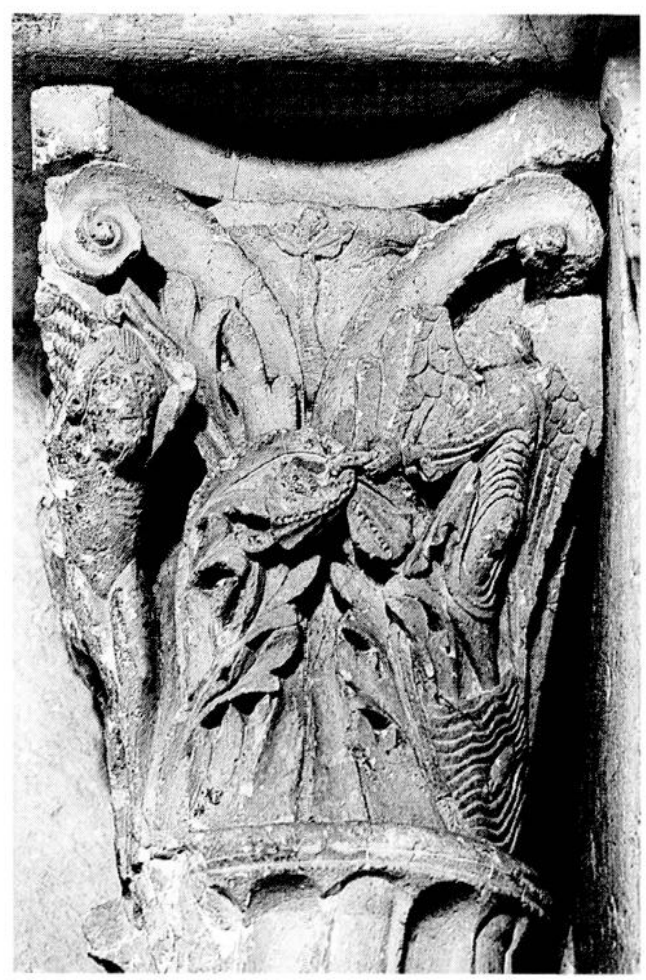

Fig. 9. - Vézliay (Yonne). Ebrasement de gauche. chapiteau de gauche (inv. Salet "nef 11 "). Paralytique portant son lit et ange descendu dans leau de la piscine probatique. (Clichés. M. Anghueben.) 
paralytique portant son lit est sculpté à gauche, accompagné d'un second malade. À droite, l'ange agite l'eau de la piscine [fig. 8 et 9 ] $^{113}$.

Cet épisode a souvent été commenté, sans doute parce qu'on y a vu très tôt une figure du baptême ${ }^{114}$. Ce miracle est aussi une image de la Passion : l'ange est le Christ, ce qui pourraitexpliquer son absence sur le chapiteau. À Vézelay, le paralytique et un autre infirme s'apprêtent à entrer dans l'église en passant devant l'ange et par l'eau du baptême. Cette image apparaît ainsi comme une reformulation du thème baptismal qui domine la partie inférieure du portail dans la figure de Jean-Baptiste. Il se peut que l'infirmité du paralytique et de son voisin renvoie également à celle des peuples de la terre, dont la guérison est opérée par le ministère du clergé.

On a aussi fait de ce miracle un prototype de la Pentecôte. Pendant que le paralytique descendait dans la piscine, un autre le précédait $(\mathrm{Jn} 5,7)$ : pour Rupert, le premier représente les Gentils qui, avant de recevoir la grâce. doivent attendre que l'Esprit-Saint descende sur les apôtres. Ensuite, après l'avoir reçue, le paralytique doit comme les Gentils s'abstenir de sacrifices, de fornication, etc. (cf. Actes 15, 28) 115 .

Le choix du sujet a peut-être été déterminé par la liturgie. En effet, comme il a été dit plus haut, les trois passages de Bède qu'on lisait à Cluny pour la Pentecôte sont des commentaires de guérisons miraculeuses tirées de l'Évangile de saint Luc. L'une d'elles concerne un paralytique auquel le Christ a dit, comme à celui de la piscine probatique : Surge tolle lectum tuum et vade in domum tuam $(5,23)$. Bède ne manque pas de faire le rapprochement entre les deux miracles, et cite même l'Évangile de saint Jean ${ }^{116}$. L'association a pu être faite également par le concepteur, et c'est peut-être pour cette raison qu'il a fait figurer deux personnages sur la partie gauche du chapiteau. Bède précise en outre que, pour le paralytique, rentrer chez soi après avoir pris son lit, revient à se rendre au Paradis : c'est ce que font les deux figures de Vézelay en se dirigeant vers l'intéricur de l'église 117.

Un réseau de liens sémantiques se tisse ainsi entre le chapiteau et le reste du portail : il rappelle à la fois Jean-Baptiste, la Pentecôte et les peuples de la terre. L'Apocalypse en revanche ne semble pas invoquéc dans l'exégèse, sauf chez saint Augustin qui voit dans la piscine les eaux au bord desquelles se tient la grande Prostituée (Ap. 17, 1) ${ }^{118}$. L'interprétation de ce passage est faite par l'autcur même de l'Apocalypse : Aquae quas vidisti ubi meretrix sedet, populi sunt, et gentes, et linguae $(17,15)$. Plus loin, saint Augustin assimile l'eau à la Passion du Christ qui doit guérir l'univers ${ }^{119}$. La présence de la grande Prostituée à côté des grandes eaux n'implique donc pas une dévalorisation de ces dernières. Il n'y a dès lors aucune contradiction entre cette lecture et celle qui en fait l'équivalent de l'eau du baptême. En revanche, le point de vue de saint Augustin offre une piste qui permettrait d'interpréter le chapiteau voisin.

\section{b) Les trois êtres monstrueux.}

Le chapiteau qui côtoie le précédent accueille, de gauche à droite, une faunesse armée d'un bouclier, un oiseau tricéphale et un dragon ailé à tête humaine dans lequel on peut voir également une sirène-oiseau à queue de serpent [fig. 10 et 11]. Son iconographie semble dériver d'un

113. P. Diemer. Stil un Ikonographie... (voir n. 34), p. 246-250. Il s'agit du chapiteau «nef II " de l'inventaire de Salet, La Madeleine... (voir n. 34).

114. Tertilimen, De baptismo V. 5-7. éd. R. R. Refolt.́, SC 35. p. 74: - saint Ambroise, De sacramentis II. 1-9. et 15, éd. B. Botre, SC 25 bis, p. 74-79, et p. 82-83: et RUPERT, in Ioh. V, CCCM IX, p. 243 et ss.

11.5. In loh. V. 5. 7b et 8-9. CCCM IX. p. 247-248.

116. In Luc. V. 20. CCSL (XXX. p. 120.

117. Ibid. V. 24, p. 122.

118. In Ioh. 17. 2. BA 72. p. 76-77.

119. Ihid. 17. 13. BA 72. p. 104-105. 


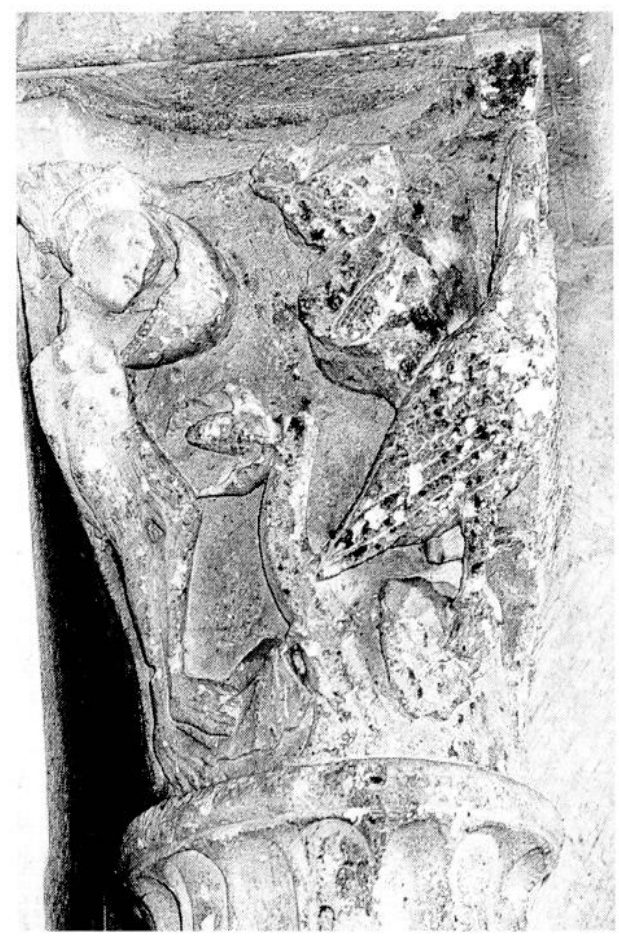

Fig. 10. - Vézsiay (Yonne). Ébrasement de gauche. chapiteau de droite (inv. Salet "nef III»). Faunesse armée dune fronde et dun bouclier. et partic postérieure de loiscau tricéphale.

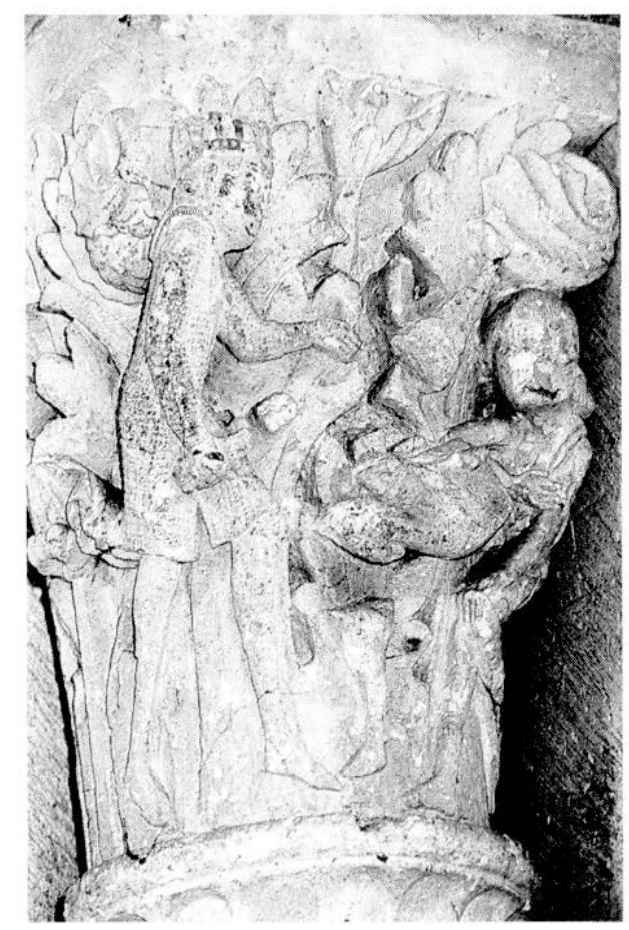

Fig. 12. - Véralay (Yonne). Éhrasement de droite. chapiteau de gauche (inv. Salet "nef IV"). Le sacrifice de Saül.

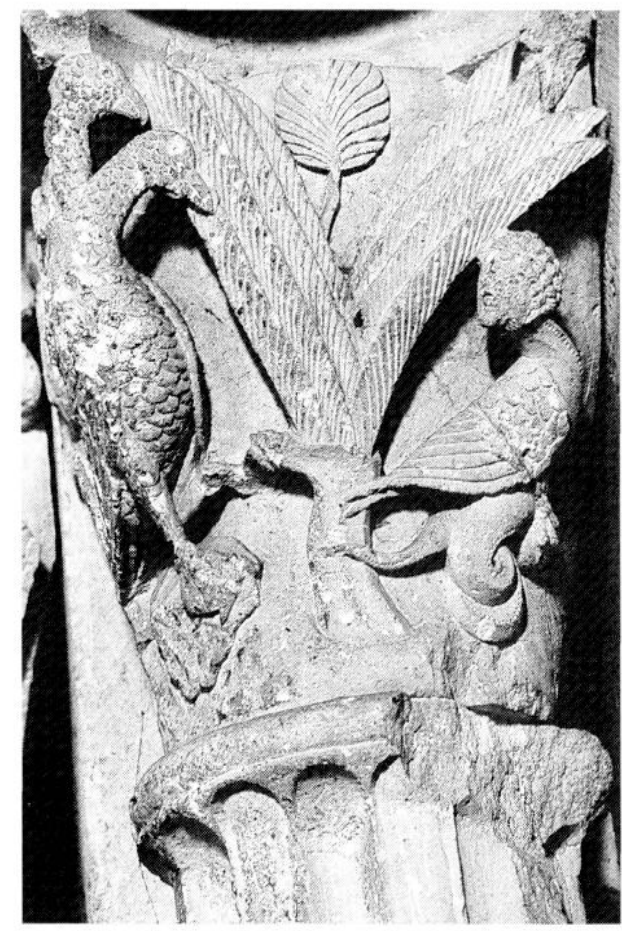

Fig. 11. - Vízrilar (Yonne). Ébrasement de gauche. chapiteau de droite (inv. Salet "nef III "). Oiseau tricéphale et dragon à tête humaine ou sirene-oiseau à queue de serpent.

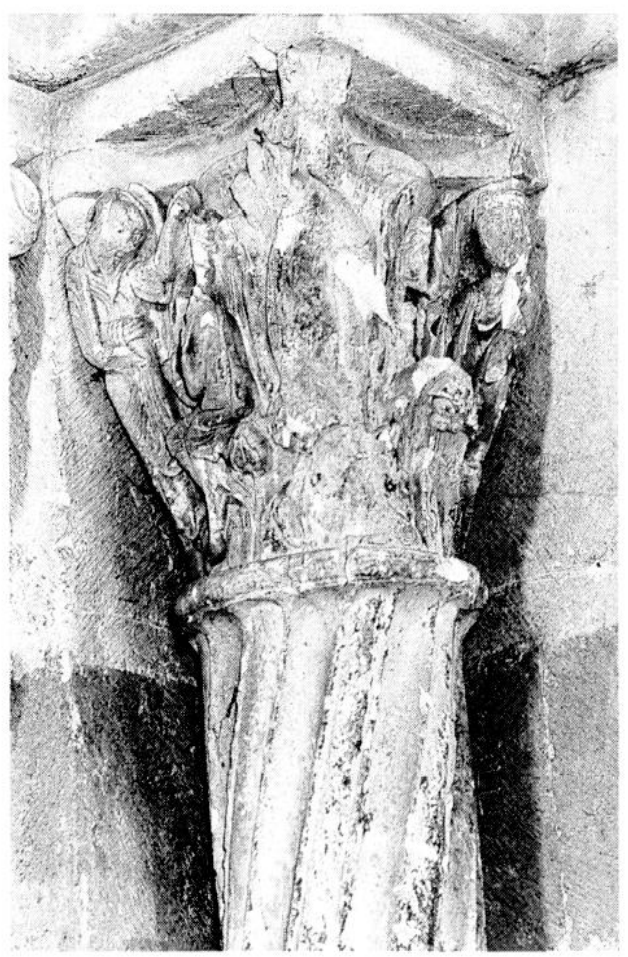

Fig. 13. - Vérilay (Yonne). Éhrasement de droile. chapiteau de droite (inv. Salet "nef $V ")$. Le sacre de David par Samuel. a gauche. et David jouant de la harpe pour Saül. à droite.

(clichés M. Angheben.) 
prototype aujourd'hui perdu qui se trouvait autrefois dans le déambulatoire de Cluny III, et qui a donné naissance à une série de variantes. toutes localisées en Bourgogne. À Cluny, c'est un faune, et non une faunesse, qui figurait à gauche ${ }^{120}$.

Pour Carol S. Pendergast, le personnage au pagne serait un onocentaure et son association avec la sirène aurait été inspirée par un passage d'Isaïe qui décrit Babylone (13,22). L'oiseau tricéphale serait alors, comme eux et comme la Bête de Babylone, une incarnation de la Luxure ${ }^{121}$.

Il faut aller plus loin et ajouter à cela que certains commentaires de l'Apocalypse font référence à un autre passage d'Isaïe, décrivant de manière très semblable la désolation qui régnera à Edom. Cette référence est utilisée non pas pour expliquer la Bête. mais la grande Babylone, qui, selon la vision, s'est faite la demeure des démons et des volatiles immondes : ... et facta est habitatio daemoniorum, et custodia omnis volucris immundae et odibilis... (18, 2). Ambroise Autpert, qui dévcloppe longuement le sujet, commence par opposer Babylone à Jérusalem : la première est l'habitat de l'antique Ennemi, la seconde est celui de Dieu. Ensuite, quand il s'agit d'évoquer les démons qui habitent Babylone, il recopie intégralement l'exégèse de Grégoire le Grand sur Isaïe 34. 13-14 122. Haymon a repris la substance de ce commentaire. et surtout la citation d'Isaïe ${ }^{123}$.

Dans ce passage. le prophète décrit les animaux qui peupleront Edom : ... et erit cubile draconum, et pascua struthionum. Et occurrent daemonia onocentauris, et pilosus clamabit alter alterum : ibi cubavit lamia et invenit sibi requiem. On y retrouve le pilosus de Cluny devenu faunesse à Vézelay : le pilosus est en effet un être semblable aux faunes et aux satyres ${ }^{124}$. Quant à l'oiseau tricéphale, il serait un de ces volatiles immondes de l'Apocalypse. La sirène, en revanche, n'est évoquée ni par l'Apocalypse, ni par Isaïe dans le passage cité par Autpert et Haymon. Néanmoins, plusicurs raisons ont pu amener le concepteur à faire figurer une sirène à droite de l'oiseau tricéphale. Premièrement, la relation entre les deux passages semblables d'Isaie devait se faire naturellement, puisqu'ils décrivent l'un comme l'autre les pilosi. De plus, la présence de l'onocentaure devait rappeler la sirène dans la mesure où tous deux sont systématiquement associés dans les bestiaires ${ }^{12.5}$.

Mais il y a surtout que les dragons, repris dans les deux passages, pouvaient être assimilés à des sirènes. Dans son commentaire sur Isaïe 13, 22, saint Jérôme définit en effet les sirènes comme des dragons volants. Il a été suivi dans cette voie par Isidore et Haymon ${ }^{126}$. Ce dernier, lorsqu'il commente le même passage, décrit les sirènes comme des dragons ailés, mais aussi comme des poissons ressemblant à des femmes ${ }^{127}$. Or, à Vézelay, le monstre de droite est une sirène-oiscau,

120. Il sagit du chapiteau "nef III" de l'inventaire de SAlet, La Madeleine... (voir n. 34). Pour le chapiteau disparu de Cluny, voir A. Eri.a.jie-Brandenburg. "Iconographie de Cluny III ». Bulletin momumental. CXXVI. 1968. p. 293-322. et en particulier p. 319; - Cons.vi, "Cluny...» (voir n. 21), p. 87. et fig. 162. Lioiseau tricéphale se retrouve également à Saint-Léger-sur-Vouzance (N. STRATFORD, "Le portail roman de Neuilly-en-Donjon". dans Congrès archéologique de France. Bourbonnais, Paris, 1991, p. 317). Montceaux-l'Étoile, Perrecy-le-Forges, Autun (bas-côté sud de la travée droite du chour. cf. D. Grivot et G. Zaknecki. Gislebertus, sculpteur d'Autum. Paris. 1960. p. 59-60, chapitcaux $n^{\prime \prime} 8$ et 24). et bien entendu Vézelay. M. T. Dari.rng. The Romanesque Architecture and Sculpture of Perrecy-les-Forges [thèse dactyl.]. Univers. of Michigan. 1994. p. 265-297. pense que le thème est apparu pour la première fois à Fleury-la-Montagne, sans l'oiseau tricéphale. Ce motif aurait été créé plus tard, à Cluny ou Perrecy. W. J. Travis. The Romanesque Sculpture of Montceaux-l'Etoile : Crossrosts of Cluny and the Brionnais (thèse dactyl.). New York Univers.. 1994, p. 85-100. identific curieusement le faune supposé avec l'onocentaure d'Isaïe et des bestiaires.

121. C. S. Pendirkgast, "The Cluny Capital of Three-Headed Bird". Gesta. XXVII. 1 et 2. 1988, p. $31-34$.

122. In Apoc. VIII. 18, 2, CCCM XXVII A, p. 672-673. cf. Moralia in Job), VII. 36.

123. In Apoc. VI, 18. PL 117, 1152 D-1153 A.

124. Haymos. Commentarium in Isaiam libri tres (in Is.) II. 13. PL 116. 789 A-B. assimile clairement les pilosi aux satyres. Cette ceuvre peut être attribuée avec certitude à Haymon, cf. D. IociNa-Prat, "L'œuvre d’Haymon d'Auxerre", dans Lécole carolingienne d'Auxerre... (voir n. 26), p. 159. Pour les pilosi et les satyres. voir R. Ber.ihimis. Wild Men in the Middle Age. A Study in Art, Sentiment and Demonology. Cambridge (Mass.). 1952, p. 96 et ss; et C. Lrcovtrix. Les monstres... (voir n. 62). p. 160.

125. F. Mc Cul.toch. Medieval Latin and French Bestiaries. Chapell Hill. 1960. p. 166.

126. Istdorl: di: Sévilde. Etymologies. Livre XII, 4, 29. Des animaux. texte établi. trad. et comm. J. Axidr. Paris. 1986. p. 156. et n. 260 pour saint Jérôme.

127. In Is. II, 13, PL 116, 789 B. Il semble en revanche qu'on n'ait pas pu assimiler les lamia d'Isaïe 34, 14. avec des sirènes. dans la mesure où Haymon en fait des femmes à jambes de cheval : ibid. II. 34. PL 116. 893 C. 
dont le corps s'achève par une queue de serpent enrouléc qui la rapproche du dragon ${ }^{128}$. On ne connaît malheureusement pas la figure qui, à Cluny, devait sans doute apparaître à droite de l'oiseau tricéphale, mais il est probable qu'elle était semblable à la sirène de Vézelay. Le commentaire d'Haymon sur l'Apocalypse - ou celui d'Autpert - et les précisions qu'il donne sur les sirènes fournissaient donc suffisamment d'éléments pour inspirer un thème aussi original.

Le caractère tricéphale de l'oiseau pose cependant un séricux problème d'interprétation, d'autant plus qu'on ne connaît rien de comparable en dehors de la série bourguignonne. La solution pourrait se trouver dans le commentaire du verset qui suit directement l'évocation du volatile monstrueux : quia de vino irae fornicationis ejus biberunt omnes gentes : et reges terrae cum illa [Babylone magna] fornicati sunt : et mercatores terrae de virtute deliciarum ejus divites facti sunt (Ap. 18. 3). Haymon, à la suite d'Autpert, en déduit qu'il existe trois types de pécheurs : les nations soumises. leurs rois et les marchands. Trois types de péchés leur correspondent : lascivia, gastrimagia, et avaritia : lascivité, voracité ou gourmandise et avarice ${ }^{129}$. Il est possible que ce développement ait donné au concepteur du chapiteau clunisien l'idée de faire figurer un oiseau tricéphale. Il aurait alors été repris à Vézclay et intégré dans le programme du portail.

Cette hypothèse se confirme quand on examine le contexte iconographique des chapiteaux d'Autun et de Saint-Léger-sur-Vouzance sur lesquels un oiseau tricéphale figure respectivement seul et flanqué d'un homme accroupi et hurlant. Il se trouve en effet que ces deux volatiles ont été associés à une représentation de la Tentation du Christ ${ }^{130}$. Or, pour l'exégèse médiévale, les trois Tentations font référence à trois péchés. La nature précise de ces péchés varie selon les autcurs. Pour Grégoire le Grand, il s'agit de la gourmandise, de l'orgueil et de l'avarice. D'autres ont remplacé la gourmandise par la concupiscence de la chair ${ }^{131}$. Quoi qu'il en soit, il semble que, même extrait de son contexte primitif, l'oiseau tricéphale a conservé globalement le sens qu'il aurait reçu initialement.

L'oiseau tricéphale de Vézelay serait done un de ces volatiles immondes qui infestent la Grande Babylone, accompagné par deux démons repris à Isaïe, à savoir une faunesse et une sirène. Le pilosus d'Isaïe est ici féminisé : peut-être a-t-on voulu concentrer sur la femme le péché de luxure. Il n'est sans doute pas fortuit que trois chapiteaux des portails latéraux soient apparentés à la même vision : on y voit un oiseau à queue de serpent, une sirène-poisson à tête d'homme [fig. 14], et un faune qui bande son arc en direction d'un de ses congénères [fig. 15] ${ }^{132}$. Le thème du chapiteau du portail central aurait donc été développé et ses composantes dispersées aux portails latéraux. Deux changements ont cependant été effectués : les faunes et la sirène ont changé de sexc. Le thème du chapiteau semble donc avoir été suffisamment souple pour susciter de nombreuses variantes, sans pour autant perdre sa substance ${ }^{133}$.

128. Cette forme de sirène se retrouve en plusieurs endroits en Bourgogne : Autun (Grivot et Zar.secki. Gisleberthis... [voir n. 120]. p. 60. chapitcau n" 24). Tïl-Chatel. Chalon-sur-Saône (chapiteau n" 27. cf. A. SAl.ss, Cathédrale de Saint-Vincent de Chalon-sur-Sâne. (halon-sur-Saône. 1965. p. 45), etc.

129. Haymox, in Ap.. VI. 18. PL 117. 1153 B.

130. A Autun. le chapiteau qui accueille loiseau tricéphale $\left(n^{\prime \prime} 8\right)$ et celui de la Tentation ( $n^{\prime \prime} 3$ ) peuvent être vus simultanément dans le bas-côté droit des travées droites du chæur. À Saint-Léger-sur-Vouzance. les deux thèmes figurent côte à côte dans labside.

131. Pour Cassien. les trois péchés sont la gourmandise. la vaine gloire et l’orgueil. cf. G. Gotil.tal, article « Tentation. Les Pères el les moines". dans DS (voir n. 12). 15. col. 226. Pour Ambroise. les trois Tentations correspondent à la gourmandise. la vanité ou vantardise et lambition (gula, iactantia, ambitio), cf. Expositio Evangelii secundum L.ucam IV. 17. éd. G. Tissot. SC 45. p. 157. Gréciolre le Graxid. $X L$ homiliarum in Evangelia I. 16. 2. PL 76. 1136 A. a remplacé lambition par lavarice. Pour BìdE enfin. In Lucae evangelium expositio I, 4. 13. éd. D. HLRST, CCSL CXX. p. 98. le premier péché est la concupiscence de la chair. Même idée che\% Paschase Radbikt. Expositio in Matheo libri XII (in Mat.) III. 4. 1-2. éd. B. PAtitus. CCCM LVI. p. 241.

132. Il sagit respectivement des chapiteaux "nef X ". " nef VI". " nef IX" de linventaire de SAfEt. La Madeleine... (voir n. 34). Pour Matiale. Iconographie... (voir n. 34), p. 18 et ss. et Dievik. Stil und Ikonographie... (voir n. 34). p. 263. loiseau monstrueux est un basilic. SALET, ibid., p. 170. l'envisage. mais avec une certaine réserve. Dilmer. ibid. p. 261-262. est le premier à envisager que les deux figures du chapiteau IX puissent être des faunes ou des êtres qui leur sont apparentés. comme les satyres ou Silène.

133. Cette recherche doit être approfondie et surtout élargie aux autres occurrences de ce thème : cela fera l'objet 
Ce thème, si l'hypothèse proposée est exacte. s’intègre parfaitement dans son environnement iconographique. D'une part. la grande Babylone se tient bien à côté des grandes eaux qui représentent les nations et qui sont également les eaux de la piscine. D’autre part, elle est. comme chez Autpert. une image antithétique de la Jérusalem céleste. fil conducteur supposé du programme. La seule chose qui paraît incohérente. c'est que les paralytiques qui désirent entrer dans léglise vont se retrouver, après le passage par les eaux du baptême. face aux monstres du chapitcau voisin. Il est possible que le concepteur en ait été conscient. mais il devait paraître difficile. voire impossible. de concilier le rapprochement piscine-Babylone avec le mouvement centripète donné aux deux infirmes. Aux portails latéraux. en revanche, les trois chapiteaux aux thèmes apparentés sont bien situés en position extérieure.

\section{c) Les deux chapiteaux de David.}

Les deux chapiteaux de droite se rattachent à l'histoire de David. Celui de gauche représente le sacrifice de Saül (I Sam. 13,9) [fig. 12], celui de droite montre. d'un côté Samuel muni d’une corne sacrant David, et de l'autre côté. à droite. David jouant de la harpe pour Saül (I Sam. 16. 14-23) [fig. 13] 134. La présence de ces trois scènes sous le tympan peut s'expliquer par un passage de la dernière vision de l'Apocalypse. Après avoir déclaré qu'il est l'alpha et l'omega, le Christ dit : Ego sum radix et genus David, stella splendida et matutina $(22,16)$. Ce rapprochement a été fait par Rupert dans son commentaire sur le premier livre des Rois : le Christ est la racine de la bona arbor c'est-à-dire de David. Cet arbre irrigué par l'huile du Saint-Esprit donna des fruits, et c'est ainsi que le Christ devint le rejeton de David ${ }^{135}$. L'onction représentée sur le chapiteau renvoie donc au passage cité ainsi qu'au thème de l'arbre, avec peut-être une allusion à l'arbre de vie de l'Apocalypse.

Le sacre de David par Samuel est aussi comparé au baptême du Christ par Jean-Baptiste ${ }^{136}$. C'est enfin la descente de l'Esprit-Saint dans un premier temps sur les apôtres et ensuite, par leur intermédiaire. sur toute l'Église ${ }^{1.37}$.

En définitive, cette scène et, par extension. les deux chapiteaux de droite, sont. comme le thème du paralytique. liés par un large réseau sémantique au reste du portail : Jean-Baptiste. la Pentecôte, et sans doute l'arbre de vie dont le Christ est à la fois la racine et le fruit.

Au terme de cet examen, une conclusion s'impose : la dernière section récapitulative de l'Apocalypse permet d'expliquer à la fois la plupart des éléments du portail et la composition qui en souligne la signification. En effet, une croix monumentale tracée sur toute la hauteur du tympan semble se superposer à un arbre de vie dont les fruits seraient les apôtres et les travaux pratiqués durant les douze mois de l'année. La disposition rayonnante de ces derniers a pu également être déterminée par le thème central de la croix-arbre de vie.

Mais le plus important est que l'Apocalypse est sans doute la seule source qui permette de justifier la présence de l'arbre de vie supposé, du zodiaque. des quatre médaillons intermédiaires et des chapiteaux de droite. Elle permet en outre de mieux comprendre la présence du fleuve qui pourrait se référer simplement au lien Pentecôte-baptême. mais dont l'association avec le trône architecturé semble directement issue de la vision apocalyptique. Il en va de même pour le trône. la figure de Jean-Baptiste et de l'Agneau. l'infirmité des peuples de la terre, la procession du linteau et plus encore pour les apôtres des ébrasements et du pilier central : le thème de la

d’une prochaine étude. Il faudra notamment expliquer pourquoi cette évocation de Babylone a été crééc à (luny et placée dans le déambulatoire. Il faudra également examiner le programme du portail de Perrecy-les-Forges.

134. Dik:mik. Stil und Ikonographie... (voir n. 34). p. 254-256. Il sagit des chapitcaux "nef IV" et "nef V" de linventaire de SAlET, La Madeleine... (voir n. 34).

135. De Sancta Trinitate et operibus eius, In libros Regum (In Reg.) I. 16. 1. éd. H. Hanck1. C(CM XXI1. p. 1232.

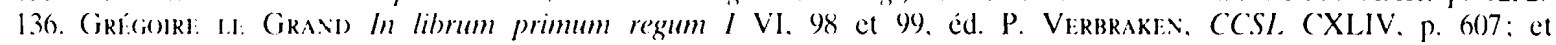
RUPF:RT. "In Reg." I. 22. C'CCM XII. p. 1231

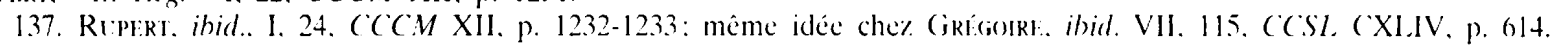




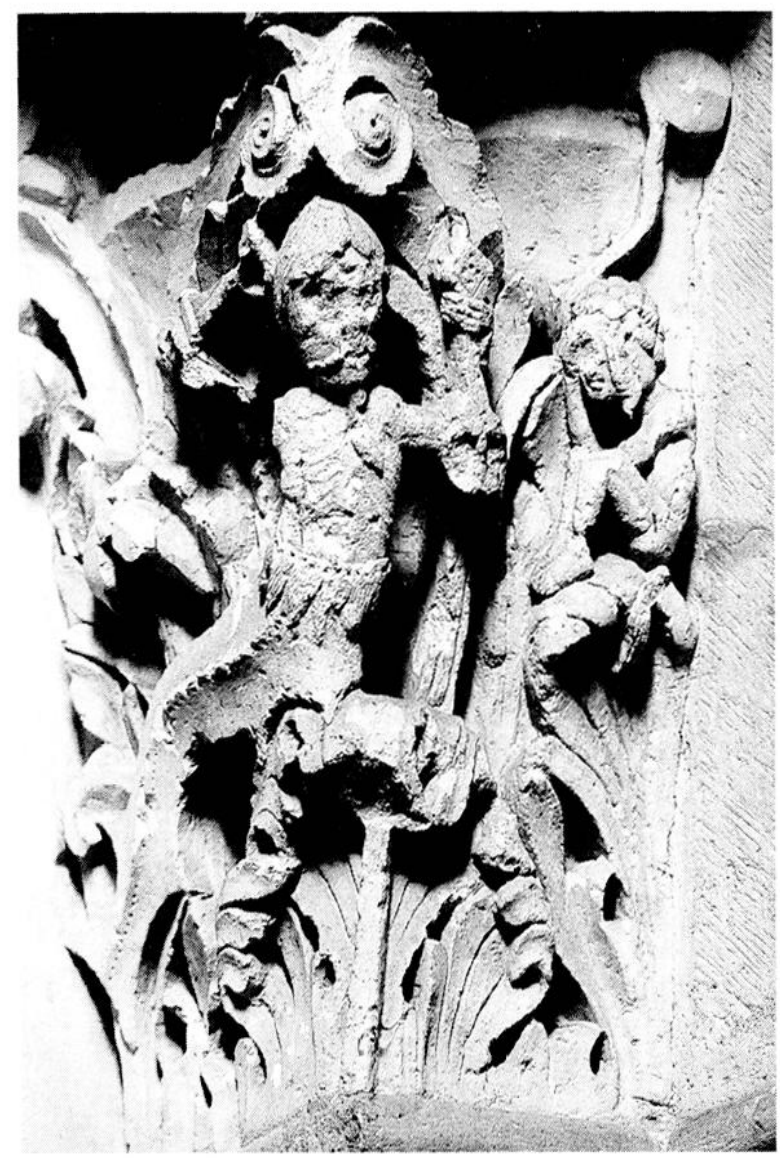

Fig. 14. - Vézzlay (Yonne). Portail sud de la nef. Ébrasement de gauche. chapiteau de gauche (inv. Salet "nef VI"). Sirène mâle tenant une vièle et levant son épée sur un petit personnage qui se bouche les oreilles.

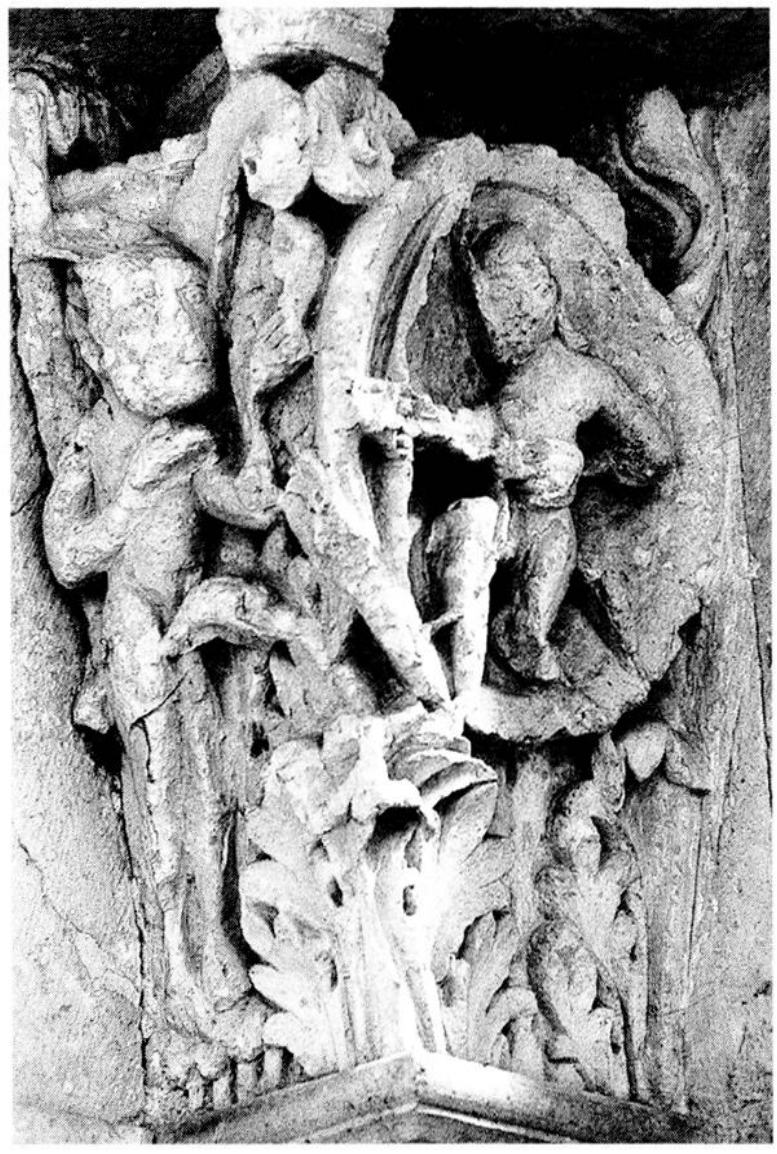

Fig. 15. - Véthlay (Yonne). Portail sud de la nef. Ébrasement de droite, chapiteau de droite (inv. Salet "nef IX "). Faune tirant à lare sur un des ses semblables.

(Clichés M. Angheben.)

Pentecôte suffisait pour suggérer ces images au concepteur, le contraignant toutefois à des détours intellectucls, alors que l'Apocalypse et ses commentaires en font pratiquement la description.

Une brève récapitulation montrera que toutes les parties du portail sont bien évoquées par l'Apocalypse. et surtout qu'elles se mettent en place avec une logique étonnante. Au centre de la Jérusalem céleste se trouve le trône de Dieu et de l'Agneau $(22,1)$ qui est en réalité celui du Christ, et dont la forme rappelle l'architecture de la civitas quadrata (21, 16). De ce trône, qui est une image de l'Église, jaillit le fleuve d'cau vive $(22,1)$ qui est à la fois le Christ. l'Esprit-Saint descendant sur les apôtres et le sacrement du baptême administré pour la première fois par Jean-Baptiste, et ensuite par les apôtres. De part et d'autre du fleuve se dresse l'arbre de vie (?) $(22,2)$, c'est-à-dire le Christ, la croix de la Passion et sans doute l'Église. Cet arbre fructifie douze mois pour que, chaque mois, il donne son fruit $(22,2)$. Les douze fruits sont les apôtres que le Christ envoya pour évangéliser les nations, sculptées ici dans les compartiments. Sur le linteau, dautres représentants de ces nations marchent dans la lumière du Christ et, peut-être accompagnés des rois de la terre, y apportent leur gloire et leur honneur $(21,24)$. Ces peuples seront guéris de l'infirmité de leur corps et de leur âme par les feuilles de l'arbre dont la fructification perpétuelle $(22,2)$ est suggérée par le zodiaque et les travaux des mois. Les Gentils, en particulier, représentés notamment par le paralytique et son voisin, après avoir été guéris par l'eau du baptême. s'apprêtent à entrer dans l'Église, accucillis par saint Pierre et saint Paul (?), tandis que dans Babylone grouillent les êtres monstrueux (18, 1). Les portes de la Jérusalem céleste sont les apôtres qui font entrer les fidèles dans l'Église par la prédication et le baptême. Aujourd'hui. ils en protègent l'accès, mais dans la Cité qui doit venir. on ne fermera 
point les portes, car il n'y aura pas de nuit $(21,25)$. En seront exclus les chiens, à savoir les juifs et les hérétiques, les hommes luxurieux, les menteurs, les empoisonneurs et autres pécheurs (22, 15). Et pour finir, le cycle de David rappelle que le Christ est à la fois la racine et le rejeton du roi musicien $(22,16)$.

Même si l'on considère que toutes ces correspondances entre le portail et l'Apocalypse n'ont pas été faites par le concepteur, leur nombre est trop important pour n'y avoir que le fruit du hasard. Certaines hypothèses sont certes plus fragiles et, par conséquent, légitimement contestables. C'est le cas notamment de l'identification des ondulations de droite avec l'arbre de vie. On peut toutefois soustraire ce dernier de la liste de correspondances, sans pour autant ébranler la cohérence du raisonnement. D’autant plus que le thème de la vie éternelle est évoqué avec suffisamment d'éloquence par le zodiaque et les travaux des mois. D'autres incertitudes ont été signalées, mais elles me semblent secondaires par rapport à la quantité de correspondances qui paraissent relier le portail à l'Apocalypse.

Ce texte a donc pu constituer, avec les Actes, la source principale du programme, complétée par un ou plusieurs commentaires dont celui d'Haymon. Pour des questions de détail, on aura sans doute consulté la Cité de Dieu, l'œuvre contemporaine de Rupert de Deutz et d'autres encore. Cela n'implique pas que le portail soit une simple transposition en image de ces textes. La part prise par le concepteur est loin d'être négligeable, notamment dans le choix et la combinaison des différents éléments, la composition de l'ensemble, et surtout dans la description des peuples de la terre, à moins que. pour ces derniers, il ne se soit servi d'un modèle perdu, peint ou sculpté 138 . La Pentecôte n'est pas exclue de ce programme, elle reste au contraire essenticlle, mais visuellement les caractères spécifiques de la scène - bras du Christ horizontaux, rayons partant des mains prennent peu de place. À mon sens, deux autres aspects dominent la composition. D'abord, et c'est le plus important, il y a la majesté du Christ. presque immobile, et dont la puissance sans limite s'exerce sur l'espace et le temps évoqués respectivement par les nations et le zodiaque ${ }^{139}$. Ensuite, il y a les apôtres, représentés en trois endroits différents, qui ont déjà commencé à accomplir leur mission, prêchant et enseignant le message du Christ, baptisant peut-être. C'est pourquoi je vois dans ce portail, outre l'épisode de la Pentecôte, une vision triomphale et atemporelle du Christ, et à travers lui de l'Eglise qu'il a fondée ce jour-là. Cette Église est en même temps la Jérusalem céleste pour laquelle æuvrent quotidiennement les prédicateurs et, par leur entremise, les apôtres.

\section{La Mission des APôtres.}

Il y a déjà été dit que, dans les textes, la Pentecôte et la Mission avaient tendance à se confondre. Dans plusicurs textes, les deux épisodes sont évoqués ensemble comme s'ils étaient inséparables, comme si l'un n'avait pas de sens sans l'autre.

On rencontre cette idée dans les coutumes de Bernard et Ulrich : le jour de la Pentecôte, à Cluny et sans doute dans la plupart des églises, on chantait en effet cette antienne : Hodie completi sunt dies Pentecostes, alleluia, hodie spiritus sanctus in igne discipulis apparuit, et tribuens eis charismatum dona, misit eos in universum mundum praedicare et testificari; qui crediderit et baptizatus fuerit salvus fuerit, alleluia ${ }^{140}$. Ce dernier passage de l'antienne est emprunté à Marc (16.16) : cette phrase prononcéc par le Christ, qui se rattache à un épisode antérieur à l'Ascension, est donc rapportée au moment où la Mission est annoncée, c'est-à-dirc après la descente de

138. Katzenellenbogen. The Central Tympanon... (voir n. 36). p. 147. Thérel. $\dot{A}$ l'origine du décor... (voir n. 1). p. 281. Dir.mir. "Das Pfingstportal..." (voir n. 1), p. 82, pensent à une influence de certains manuscrits byzantins sur la description des peuples de la terre.

139. Même idée chez Katzenelifenbogien. The Central Tympanon... (voir n. 36). p. 146.

140. BerNakd). Ordo... (voir n. 19), p. 322: - Ul.RICH, Antiquiores consuetudines cluniacensis monasterii, PL 149. 671 D. Pour le texte de laantienne, voir R.-J. Hessert, Corpus antiphonalium officii, Rome, 1963, 79. III. p. $255 . \mathrm{n}^{\prime \prime} 3096$. Elle était chantée le dimanche de la Pentecôte et a loctave de cette fête. 
l'Esprit-Saint. Notons aussi que la liturgie clunisienne a également associé l'envoi du Paraclet et la première Mission des apôtres. celle qui se situe entre les premiers miracles du Christ et la Transfiguration ${ }^{1+1}$.

Dans les commentaires de la dernière section de l'Apocalypse, certains passages ont aussi évoqué la Mission. Chez Rupert. par exemple, l’arbre de vie est comparé au Christ qui choisit et envoya les douze apôtres ${ }^{142}$. Cette idée s'accorde encore une fois avec l'image où l'on voit déjà les disciples s'agiter et exhiber leur livre.

Si désormais il semble difficile de voir dans la scène du tympan l'annonce de la Mission avant l'Ascension, il faut observer en revanche que son application a déjà commencé. La scène centrale du tympan évoquerait donc à la fois la descente de l'Esprit-Saint et le début de la Mission, qui doit être considérée dans la longue durée, puisqu'elle est perpétuée par l'Église. C'est pourquoi je crois qu'en plus d'une représentation simultanée de la Pentecôte et de la Mission, il s’agit d’une théophanie atemporelle dont l'actualité se prolonge jusqu'à la seconde Parousie.

\section{la Pentecôte et l'iconographie des portails latéraux.}

Il convient à présent de confronter ces conclusions aux sujets des portails latéraux. Celui de droite rassemble les premiers épisodes de l'Incarnation : Annonciation, Visitation, Nativité et Adoration des Mages [fig. 16], celui de gauche est lié aux derniers instants de la vie du Christ : les Pèlerins d'Emmaüs et l'Apparition de Jésus à ses disciples avant l'Ascension (Lc 24, 36-51) [fig. 17]. La première lecture, la plus simple, induit à voir dans les trois portails un cycle christologique qui s'articule sur les grandes idées du dogme : Incarnation, Rédemption et continuation de l'œuvre du Christ à travers l'Église ${ }^{14.3}$. On retrouve un programme pratiquement identique à San Marco de Venise : les thèmes des mosaïques des trois coupoles axiales sont de fait, en partant de l'est, l'Incarnation, l'Ascension et la Pentecôte ${ }^{144}$.

Il y a ensuite l'approche liturgique, directement liée à la première. Pour Marie-Louise Thérel et Peter Diemer, les portails se rattachent aux grandes fêtes de l'année liturgique : Noël, Pâques et la Pentecôte. Partant de cette constatation, Peter Diemer associe l'évocation de ces solennités à la fonction du narthex : c'est là en effet que, d'après les coutumes clunisiennes, les processions se formaient avant d'entrer dans l'église ${ }^{145}$. Les coutumes de Bernard et Ulrich prévoient d'ailleurs une station dans la galiléc le jour de la Pentecôte : c'est du reste à ce moment qu'était entonnée l'antienne Hodie completi sunt. Il faut ajouter à cela qu'un arrêt était également organisé pour la fête de l'Ascension. En revanche, rien n'est signalé pour la fête de la Nativité ou pour l'Épiphanie ${ }^{1+6}$. Compte tenu des liens très étroits qui unissaient Cluny et Vézelay, on peut supposer que de telles stations étaient également prévues dans le narthex de Vézelay.

Marie-Louise Thérel complète cette lecture en y intégrant le portail central du narthex. Elle signale qu'au XII ${ }^{\mathfrak{C}}$ s., l'année liturgique se terminait le dimanche après la Pentecôte, lorsqu'on lisait l'Évangile de Matthieu sur le Jugement dernier (24, 15-35). Or, c'est précisément ce thème qui

141. Bì:De. in Luc. IX. 1-6. CCSL CXX. p. 194-196. Ce texte était lu à Cluny pour la fête de la Pentecôte. cf. E1AIX. Homéliaires patristiques... (voir n. 70), p. 106.

142. In Apoc. XII. 22. PL, 169. 1207 A. Primase commente le verset 22. 4. en le rapprochant de Mat. 28 . 19 : "Vous baptisere\% au nom du Pire..." in Apoc. V. 22. 4. CCSL X(II. p. 303.

143. (elle lecture a été faite par Marie-Louise Thíke... Á l'origine du décor... (voir n. 1). p. 280.

144. La source des langues de feu est un trône sur lequel ont été déposés un livre et la colombe du Saint-Esprit. Pour Otto Dents. The Mosaic of San Marco, Venice. (hicago/Londres. 1984. t. I. p. 152. il sagit dune figure de la Trinité. Que le Père soit évoqué ou non dans celte image. il reste que le (hrist se trouve bien à lorigine des langues de feu.

14.5. Dif:yer. "Das Pfingstportal.." (voir n. 1). p. 97 et ss. I.e rôle symbolique et liturgique du narthex ou galilée na malheurcusement pas été complètement dégagé. cela n’empêche pas qu il puisse exister un rapport entre ce rôle et les choix iconographiques qui ont été opérés pour cet espace.

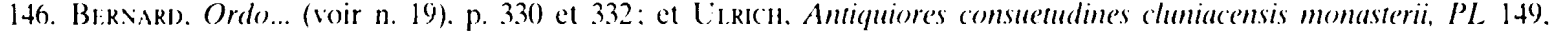
$670 \mathrm{D}$ et $671 \mathrm{D}$. 


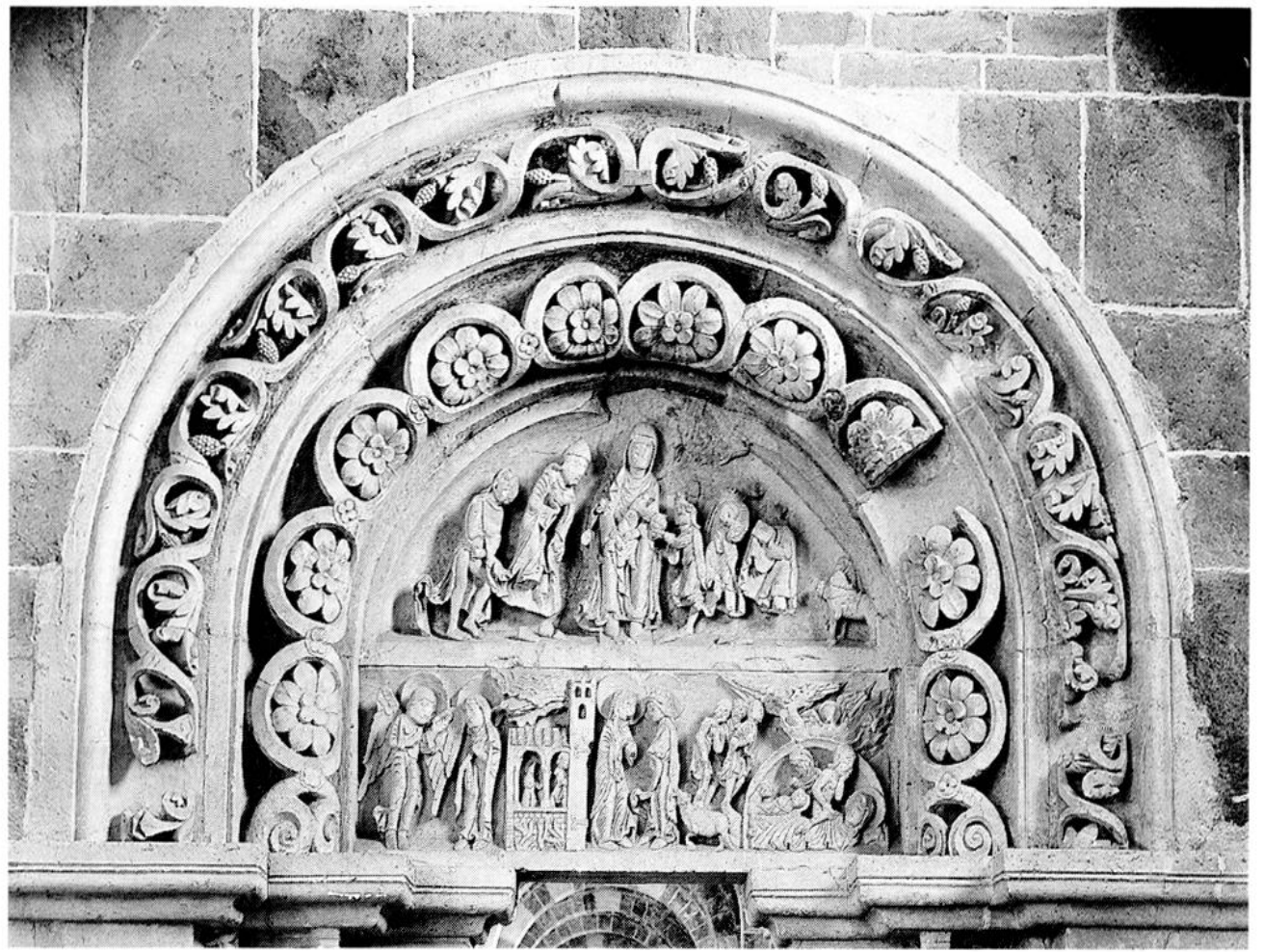

Fig. 16. - VézfitaY (Yonne). Portail sud de la nef. Vue densemble.

Fig. 17. - Vézelay (Yonne). Portail nord de la nef. Vue densemble. (Clichés Paris, Caisse Nat. Monum. Histor., nég. 52 P 27.5 et 52 P 273.) 
figurait sur le portail extérieur aujourdhui illisible. mais dont on possède des descriptions anciennes ${ }^{1+7}$. Les sujets des quatre portails semblent done bien liés aux temps forts de la liturgie. Je voudrais cependant proposer une troisième lecture qui ne s'oppose nullement aux deux premières. mais qui les complète et met en lumière les points communs qui existent entre les trois portails. En effet, si l'on accepte que celui du centre exalte la fondation et l'actualité de l'Église-Jérusalem céleste, on sera également interpellé par la présence de ce thème aux portails latéraux. À droite est représentéc la Nativité: or certains exégètes rappellent que Bethléem signifie domus panis, à l'instar de l'église où les croyants sont rassasiés par une nourriture angélique ${ }^{148}$. Quant à l'Adoration des Mages, clle a souvent été comprise comme la reconnaissance du Christ par les Gentils. Comme les rois de l'Apocalypse $(21,24)$, ils apportent des présents au Seigneur ${ }^{1+9}$. Voilà done deux aspects du portail de droite qui le rattachent sćmantiquement au portail de la Pentecôte. De plus, les chapiteaux de David, situés à droite du portail central renvoient aux ancêtres du Christ, et donc à la Nativité. Le plus important sans doute est qu'au XII" s.. la Vierge. avec ousans enfant, représente symboliquement l'Église ${ }^{150}:$ c'est ce que suggère à Vézelay sa position axiale et frontale.

À gauche, c'est l'histoire des pèlerins d'Emmaüs qui établit le lien avec le portail central, dans la mesure où elle est considérée comme une préfiguration de l'eucharistie. La scène fait done également référence à l'espace ecclésial où le sacrement est administré. Ce lien est corroboré par les analogies structurelles qui existent entre l'auberge où se déroule la scène, et l'architecture des églises romanes.

On notera qu’à la cathédrale de Chalon-sur-Saône et à Laizy, près d’Autun, la scène est représentée sur un chapiteau du chœur ${ }^{151}$. À Gourdon, la Nativité et les pèlerins d'Emmaüs sont peints face à face sur les parois du chœur ${ }^{152}$. Les deux scènes sont peut-être la deuxième et l'avant-dernière d'un cycle christologique qui devait se déployer dans la nef et revenir vers le chour ${ }^{15.3}$. Mais il est sans doute significatif que ces peintures qui évoquent l'eucharistie et l'Église. comme les deux chapitaux cités, se trouvent dans la partie la plus sacrée de l'édifice, celle où est célébré le mystère de l'eucharistic, celle où apparaissent - au cul-de-four - le Christ et les quatre Vivants, et qui est une figure de la Jérusalem céleste ${ }^{154}$. La similitude avec l'ensemble de Vézelay

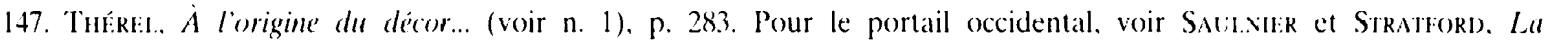
sculpture... (voir n. 28), p. 245-246.

148. Paschase Radbekt, in Mat. Il, 2. I. CCCM LVI. p. 148.

149. Théré., $A$ lorigine du décor... (voir n. 1). p. 280. fait celte lecture pour Anzy-le-Duc et Neuilly-en-Donjon. mais ne l'envisage pas pour Vézelay.

150. Pour la notion el la représentation de la Vierge-Église. voir M.-L. THíki:. Les symboles de l" Ecclesia" dans la création iconographique de l'art chrétien du ur' all ir s.. Rome. 1973. et A l'origine du décor... (voir n. 1): -

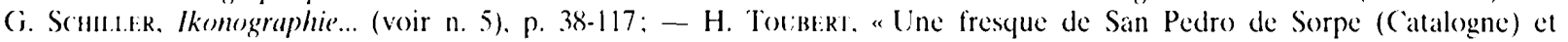
le thème de larbor bena-ecelesia, arbor mala-sinagoga" dans Un art dirigé... (voir n. 42). p. 65-89: - P. SkUbIS̈r:wski. "Ecclesia, Christianitas, Regnum et Sacerdotium dans lart des $\mathrm{x}^{\circ}-\mathrm{xl}^{*}$ s. Idées et structures des images". Cahiers de civilisation médiévale. XXVIII. 1985. p. 133-179): et "L.es impondérables de la recherche iconographique. $A$ propos d'un livre récent sur te thème de la glorification de l'Église et de la Vierge dans l'art médiéval ». ibid.. XXX. 1987. p. 145-153: et D. Risso. "Les représentations mariales dans laart d'Oecident du moven áge. Essai sur la formation d'une tradition

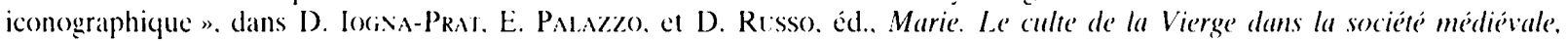
Paris. 1996. p. 17.3-291. et en particulier pour les $\mathrm{xi}^{\circ}$-XII $\mathrm{s}$ s. p. 232 et ss.

151. Dans le cheeur de la cathédrale d'Autun, un chapiteau représente la rencontre entre le ('hrist et les pélerins

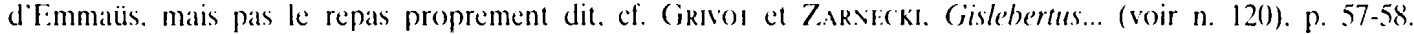

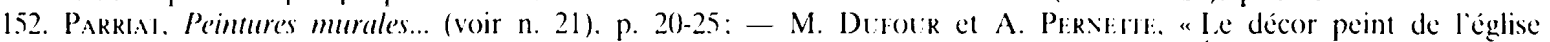

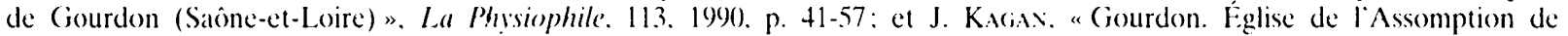
la sainte Vierge". dans Docre et dazur... (voir n. 21). p. 220-221. La premiere scene de ce qui a pu être un cycle christologigue est l'Annonciation. La dernière a disparu : on peut toutefois supposer quion $r$ a représenté l'Ascension ou la Pentecote. Si cest la Pentecote qui figurait dans la lacune. la descente du Saint-Esprit sur les apotres aurait correspondu de maniere significative avec celle qui sest produite sur Marie lors de l'Annonciation représentée en face.

153. (et ensemble na peutêtre jamais été réalisé. mais ce qui compte. ceest qu il a pu être conçu de cette manière.

154. Pour la symbolique de l'Eglise comme Jérusalem céleste. voir J. Saltr. Symbolik des Kirchenbaïdes und seiner Ausstatumg in der Auffassung des Vittelalters. 20 éd. Pribourg-en-Brisgau. 1924. notamment p. 104: et (i. Baxb.Maxi. "Die vorgotische Kirche als Himmekstadt ". Frühmittelallerliche Studien. 6. 1972. p. 67 et ss. Pour lapplication de cetle

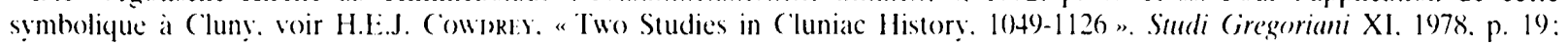


est presque complète, puisque les deux scènes narratives sont disposées de part et d'autre d'une théophanie.

Toutes ces considérations se maintiennent essentiellement dans la sphère symbolique. Il faut donc, pour terminer, poser la question de l'ancrage du programme dans l'idéologie et les événements contemporains. Si l'Apocalypse est bien, avec les Actes, la source principale du portail, cela permettrait peut-être de mieux cerner les objectifs poursuvis par le concepteur dans le choix du sujet. En effet, on a vu que, pour les exégètes, la Jérusalem céleste se réfère régulièrement à l'Église actuelle. Cette Église serait donc celle des premiers chrétiens ${ }^{155}$, celle, parfaite, qui doit venir, mais aussi celle qui prie et qui lutte quotidiennement. On peut du reste y voir plus particulièrement l'Église de Rome ou celle de Vézelay puisqu'elles ont les mêmes patrons représentés en différents endroits du portail.

Plusicurs auteurs ont voulu préciser davantage les références historiques ou idéologiques introduites dans le programme : on a proposé un rappel de la première croisade. une affirmation du filioque et des droits de l'abbaye, une allusion à la liturgie. une illustration de l'ecclésiologie clunisienne d'inspiration grégorienne, une image de la puissance de l'abbaye à la manière d'un arc triomphal ${ }^{156}$. Le débat est loin d'être clos, mais cette étude devrait confirmer que l'Église contemporaine du portail est bien concernée par le programme iconographique.

Marcel ANGHEBEN

23. rue du Bois de Linthout, B-1200 BRUXELLES

et D. Iogina-Prat, "Cluny, citadelle céleste". dans G. Diby et M. LaciotTt. éd.. Le moyen age. Histoire artistique de l'Europe. Paris. 1995. p. 224-232.

155. Pour Peter Dikmir. "Das Pfingstportal..." (voir n. 1), 1985. la Pentecôte fait d’abord référence à l'Église des premiers chrétiens qui étaient. pour Odon et Odilon. un modèle de la vie monastique.

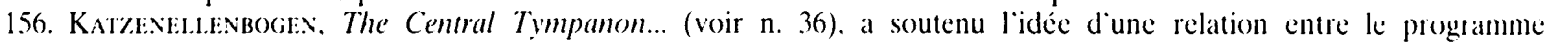
iconographique du portail central et la prédication de la deuxième croisade. Dautres. avant et après lui. ont proposé cette hypothèse. mais son étude est la mieux argumentée : voir le résumé de la discussion che\% Dif:mir. "Das Pfingstportal..." (voir n. 1), p. 89-92. TAYIor. "The Pentecost..." (voir n" 1), a pensé à une allusion au Filioque. aux droits du monastère face à ses ennemis, et à l'Église réformée. Dilmer, ibid., p. 102-104. on l'a vu. a mis l'accent sur le rôle de la galilée et de la liturgie dans les choix iconographiques. Thékel. $\dot{A}$ lórigine du décor... (voir n. 1). p. 283-284. a signalé des ressemblances entre le portail et l'ouvre de Pierre le Vénérable, mais elle na pas établi de relation directe entre les deux. Le programme iconographique illustre plutôt l'ecclésiologie clunisienne modelée par celle des grégoriens. comme elle, je crois que, malgré ces analogies et celles que jai signalées, on ne peut pas considérer que lexuvre de l'abbé de Cluny a pu exercer une influence directe sur l'eeuvre sculptée. Pour Feidomavis. The Narthex Portal... (voir n. 1). p. 146-203. le portail a été conçu comme un are triomphal destiné à affirmer la puissance de labbaye. 